Article

\title{
Sensor-Assisted Assessment of the Tribological Behavior Patterns of AA7075 Hybrid MMC Reinforced with Multi-Wall Carbon Nanotubes and Pulverized Fuel Ash
}

\author{
Senthil Kumaran Selvaraj ${ }^{1}\left(\mathbb{D}\right.$, Kathiravan Srinivasan $^{2}\left(\mathbb{D}\right.$, Ramesh Kumar $^{3}{ }^{3}(\mathbb{D}$ \\ and Yuh-Chung $\mathrm{Hu}^{4, *(D)}$ \\ 1 Department of Manufacturing Engineering, School of Mechanical Engineering, Vellore Institute of \\ Technology (VIT), Vellore 632014, India; senthilkumaran.s@vit.ac.in \\ 2 School of Information Technology and Engineering, Vellore Institute of Technology (VIT), \\ Vellore 632014, India; kathiravan.srinivasan@vit.ac.in \\ 3 School of Mechanical Engineering, SASTRA Deemed to be University, Thanjavur 613401, India; \\ srk1306@gmail.com \\ 4 Department of Mechanical and Electromechanical Engineering, National ILan University, No. 1, Sec. 1, \\ Shennong Rd., ILan City 26041, ILan County, Taiwan \\ * Correspondence: ychu@niu.edu.tw
}

Received: 30 April 2020; Accepted: 2 June 2020; Published: 5 June 2020

\begin{abstract}
In recent years, the deployment of sensors and other ancillary technologies has turned out to be vital in the investigation of tribological behavioral patterns of composites. The tribological behavioral patterns of AA7075 hybrid metal matrix composites (MMCs) reinforced with multi-wall carbon nanotubes (MWCNTs), and pulverized fuel ash (PFA) were investigated in this work. The stir casting technique was used to fabricate the composites. The mechanical properties such as tensile strength and hardness were determined for the fabricated material. Besides, microstructure analysis was performed for these AA7075 hybrid MMCs reinforced with MWCNTs and pulverized fuel ash. A pin-on-disc wear testing setup was used to evaluate the wear rate, in which the EN 31 steel disc was used as the counter-face. Taguchi's design of the experiments was used to optimize the input parameters that impact the characteristics of the hybrid composites, and ANOVA (analysis of variance) was used to determine the contribution of input parameters on the wear behavior. Electrical discharge machining (EDM) was conducted on the AA7075 hybrid metal matrix composites using a copper electrode for determining the material removal rate. These investigations and the results were utilized for determining the optimized output process parameter values of the AA7075 metal matrix composite.
\end{abstract}

Keywords: AA7075; multi-wall carbon nanotubes; MMC; material removal rate; pulverized fuel ash; tribology

\section{Introduction}

In the present era, composite materials are deployed in various manufacturing sectors, and it plays such a key role in many industries, including aerospace, automobile, bearing, biomedical, defense, and construction firms [1-5]. The carbon nanotubes (CNTs) were considered to be the favorite contenders for improving the characteristics of the composites [6]. The fabrication of the aluminium reinforced with fly ash composites was accomplished through the stir casting process [7-9]. Besides, the tribological assessment of these metal matrix composites (MMCs) indicated that there was a linear 
increase in wear resistance with an upsurge in the fly ash concentration. Furthermore, it was witnessed that the tribological behavior of these composites was influenced by factors such as the applied load, and the size, volume, and nature of the reinforcement particles [9]. Besides, in these composites, it was witnessed that an increase in weight percentage of fly ash causes a corresponding decrease in the wear rate. However, it can also be observed that the uniform distribution of fly ash causes an increase in the hardness of the fabricated composites [10]. The aluminium 7075 hybrid MMCs were prepared through the stir casting process, and the parameters were analyzed using the Taguchi approach [11].

The mechanical properties of Al2024 reinforced with one weight percentage CNTs were investigated [12]. Moreover, the wear behavior of aluminium based synthesized composites were assessed [13-15]. Aluminium was reinforced with carbon nanotubes using the induction melting process for aerospace applications [16]. Moreover, it was observed that there was a refinement in crystallite size and augmentation in the lattice strain in the fabricated aluminum/CNTs composites. The reinforcement of AA7075 with Si-Fly ash was investigated, and it was witnessed in the composites that there was a linear increase in tensile strength, hardness, and yield strength when compared to the base alloy [17-19]. Al7075 was reinforced with $\mathrm{Al}_{2} \mathrm{O}_{3}$ through the stir casting method, and it was witnessed that the corrosion rate of Al7075 increases with an increase in reinforcement volume. Furthermore, it was noted that Al7075 endures severe corrosion in seawater environments compared to in industrial settings [20]. The tribological and mechanical behavior of Al7075 reinforced with graphite was studied under dry sliding conditions, and it was witnessed that the minimum friction rate at five weight percent of the graphite content [21].

The PFA $\mathrm{B}_{4} \mathrm{C}$ particles were incorporated into the Al7075 matrix by using plasma-activated sintering, and it was observed that the composites exhibited improved mechanical properties with a 7.5 wt.\% of $\mathrm{B}_{4} \mathrm{C}[22,23]$. The mechanical and tribological characteristics of AA7075 reinforced with five weight percentage of $\mathrm{TiB}_{2}$ using the ultrasound-assisted casting process, and it was observed that the synthesized material displayed superior wear resistance to the base metal alloy [24,25]. The AA7075 alloy reinforced with alumina through the stir casting process was investigated, and the results showed that synthesized material demonstrated a lower wear rate and reduced coefficient of friction than the base metal matrix [26-28]. It can be witnessed from the above articles that creating a high-performance $\mathrm{MMC}$ is progressing at a great pace. On the other hand, there is not much focus in the area of combining (in the right proportion) multi-wall carbon nanotubes (MWCNTs) and pulverized fuel ash (PFA) with AA7075 as the base material for creating a new metal matrix composite.

Moreover, the AA7075 is commercially referred to as "aerospace alloy" possessing extraordinary properties such as low weight and high tensile strength. In this work, we have fabricated a hybrid metal matrix composite with AA7075 as the base material that was reinforced with MWCNTs and PFA for creating new metal matrix composite through the stir casting method. It was witnessed that the inclusion of the pulverized fuel ash (PFA) to the base material improved the wear resistance and hardness of the resulting composite material. Moreover, the multi-walled carbon nanotubes were tested to have a tensile strength of $63 \mathrm{GPa}$, and it possessed a low density of 1.3 to $1.4 \mathrm{~g} / \mathrm{cm}^{3}$. Further, in house tribological tests revealed that the multi-walled carbon nanotubes are the strongest and stiffest materials concerning factors such as tensile strength and elastic modulus. The strategy of this combination was aimed at developing the AA7075 hybrid MMC that is suitable for aerospace applications. Besides, the assessment of the mechanical properties and wear behavior of this synthesized composite demonstrated supreme results, which will widen its application in other industrial sectors. 


\section{Materials and Methods}

The aluminium alloy 7075-T6 material is characterized by zinc as the primary alloying material with lower compositions of Magnesium, Copper, and few other smaller elements. The base alloy AA7075 was procured from Ultimate Enterprises, Chennai, India, with the standard dimension of (Ø $20 \mathrm{~mm} \times 1000 \mathrm{~mm}$ ). Multi-walled carbon nano tubes manufactured through the chemical vapor deposition method was obtained with a purity of $99 \%$ from Ad Nanotechnologies, Bengaluru, India. The Class F pulverized fuel ash was purchased from Neyveli Lignite Cooperation Ltd, Neyveli, India.

The crucible and the stirrer were coated with graphite paste to ensure the non-adhesiveness of the molten with them. The furnace heated up to a temperature of $900{ }^{\circ} \mathrm{C}$ (above the melting point of aluminum, $670{ }^{\circ} \mathrm{C}$ ), with the pre-weight AA7075 of $1000 \mathrm{~g}$, converting the solid metal to molten aluminum.

The pre-heated and pre-weighted reinforcements such as MWCNTs and PFA were added to the furnace. Moreover, for every unit percentage increase in temperature, leading to the melting of AA7075, a standard $1 \%$ of magnesium was added to the furnace. Furthermore, this process increased the wettability and adhesiveness of the reinforcements with the base material.

The furnace was left for the stirring time of $15 \mathrm{~min}$ and stirring speed of 200-300 rpm for the homogenous distribution of reinforcements. The sample with a $10 \mathrm{~mm}$ diameter and $5 \mathrm{~mm}$ in height was taken for the microstructure analysis. The total samples used were five, which is of five different compositions (0, 1, 2, 3, and 4). The polished sample was etched using Keller's reagent (MilliporeSigma, St. Louis, MO, USA) with the composition: $-2 \mathrm{~mL} \mathrm{HF} \mathrm{(48 \% )} 3 \mathrm{~mL} \mathrm{HCl}+5 \mathrm{~mL} \mathrm{HNO}_{3}+190 \mathrm{~mL} \mathrm{H}_{2} \mathrm{O}$. Further, this etchant aided in revealing the grain boundary contrasts and the presence of precipitates in the several synthesized composites. The hardness value was taken for five samples of different compositions $(0,1,2,3$, and 4$)$. The applied load was 100 kilogram-force (kgf). Then, the indenter was moved $1 \mathrm{~mm}$ from the previous spot, and the hardness value was measured. Five values were taken for each sample. The resulting unrecovered indentation diagonals were measured and averaged to give the value in millimeter. The mean values of the five results gave the hardness value of the sample. These length measurements were used to calculate the Vickers Hardness Number (VHN).

The tensile test specimen was prepared as per the ASTM-E8 standards. The fabricated sample had the following dimensions: outer diameter is $15 \mathrm{~mm}$, gauge length is $30 \mathrm{~mm}$, the diameter of the reduced section is $6 \mathrm{~mm}$. The tensile test was accomplished using the Instron machine (Instron, Norwood, MA, USA). In this experiment, only the measurement of the ultimate tensile strength (UTS) is required. The UTS is the maximum amount of stress a material can withstand before failure. Furthermore, this value is the maximum value on the stress-strain graph. By determining the UTS of the material, the maximum strength of the material can be identified.

Pin on a disc is a standard procedure for testing the wear rate of the material through the frictional action of the pin over the highly harder disc (EN31 Stainless Steel). Further, this procedure discovers the pre-determined load acting upon the pin. Besides, the procedure accomplished using the pin on the disc setup. The input parameters used for identifying the wear behavior are composites (wt \%), load $(\mathrm{N})$, speed (rpm), and time (minutes). Each sample was weighed before and after the procedure to determine the weight loss. The wear rate was also calculated from the obtained results. The setup is shown in Figure 1. 


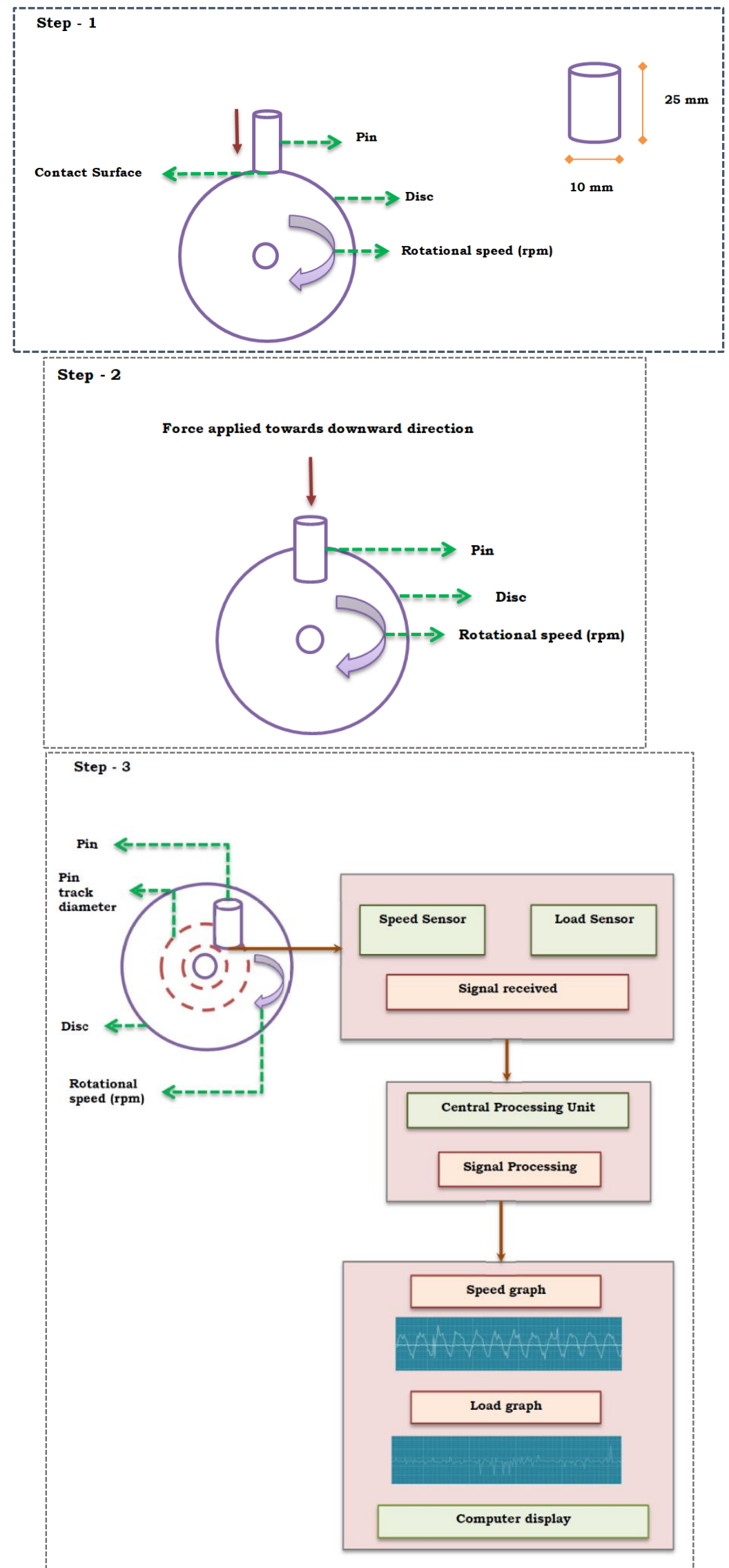

Figure 1. Step 1-3 for speed and load determination using different sensors in the tribology test. 
The wire used for this procedure is brass. Usually, the hardness value of the wire is more than that of the material to be cut. The wire is wound over the machine and is arranged accordingly to cut the material. The dimension of the sample is $17 \mathrm{~mm}$ diameter and $35 \mathrm{~mm}$ height. The sample is held between two clamps and is fixed at both ends. The parameters taken are pulse-on current, pulse-off current, and peak current. The samples must be weighed before and after the procedure to find a weight loss of the sample. With the obtained values, the MRR of the samples is found.

$\mathrm{X}$-ray powder diffraction (XRD) is a technique used for the identification of the phase of a material. Here the number of samples taken is five. One each for different compositions $(0,1,2,3,4)$. The range of angle taken is $10^{\circ}$ to $90^{\circ}$. The peaks are analyzed between these angles. The dimension of the sample taken is $10 \mathrm{~mm}$ diameter and $5 \mathrm{~mm}$ height. The analysis was done using the Panalytical X'pert Pro $\mathrm{Cu}-\mathrm{Ka}$-band $1.93251^{\circ} \mathrm{A}$ (Malvern Panalytical Ltd., Malvern, UK).

\section{Material Characterization}

\subsection{Details of Experimental Design}

The experimental design is most essential to carry out experiments to arrive at a precise output response. Furthermore, this could help us in determining the input variables for various trials to get validated output parameters. In this study, we have used the Taguchi experimental design for determining the wear rate, weight loss, and material removal rate.

\section{Design of Experiments}

- Wear Rate and Weight Loss

With the help of MINITAB, we have found that the $\mathrm{L}_{25}$ orthogonal array is best suited for our approach of design in determining the wear rate and weight loss with the various sets of factors and levels given below in Table 1.

Table 1. Input parameters of wear rate, weight loss.

\begin{tabular}{lll}
\hline S1.No & Input Parameter & Range \\
\hline 1 & Composites (Wt \%) & $0,1,2,3,4,5$ \\
2 & Load (N) & $10,15,20,25,30$ \\
3 & Speed (rpm) & $250,300,340,400,450$ \\
4 & Time (min) & $5,7,9,11,13$ \\
\hline
\end{tabular}

- Material Removal Rate

Determining the input parameters to find the material removal rate of the developed composites with different levels and factors is fed to MINITAB. Further, this statistical analysis software helps in finding necessary input variables for various trials, as in Table 2. It is also found that $\mathrm{L}_{25}$ is best suited orthogonal chart for this experiment.

Table 2. Input parameters of material removal rate.

\begin{tabular}{lll}
\hline Sl. No & Input Parameter & Range \\
\hline 1 & Composites $(\mathrm{Wt} \%)$ & $0,1,2,3,4,5$ \\
2 & Pulse on $(\mu \mathrm{S})$ & $12,24,36,48,60$ \\
3 & Pulse off $(\mu \mathrm{S})$ & $4,5,6,7,8$ \\
4 & Current $(\mathrm{A})$ & $1,2,3,4,5$ \\
\hline
\end{tabular}

\subsection{Constraints}

The main constraints that affect the further development of this work are the cost of MWCNTs, and as we all know, the wettability of reinforcements with the base alloy matrix. The previous scenario was 
due to the different thermal stability of the added reinforcements leading to agglomeration formation. Furthermore, this leads to improper nucleation growth that hinders the mechanical properties such as hardness and tensile strength. Moreover, this could further weaken the strengthening mechanism, such as grain refinement and the dislocation strengthening phenomenon which significantly affect the properties.

Sometimes, the type of PFA and its properties procured may differ with different thermal power plants, leading to deteriorating properties of the developed metal matrix composites. PFA is very poor in dispersion with the base alloy and affects the hardness of the material in a greater context. There is no uniform dimensional stability of the casted product due to shrinkage that happens to base alloy. Besides, the predetermination of allowance is a complicated process as its reinforcements are added to the base alloy, because of there being much less knowledge on theshrinkage properties of the reinforced matrix composites.

\section{Results and Discussion}

The microstructure was taken by an inverted microscope of AA 7075 reinforced with MWCNTs and PFA with various Wt $\%(0,1,2,3,4)$. The microstructure reveals that MWCNT and PFA were mixed and distributed evenly. Figure 2a shows the microstructure of the AA 7075 matrix. Aluminium alloy 7075 particles occupied the primary part, and the rest of the portions were mixed with MWCNTs and PFA particles with irregular shapes, and also the reinforcements were successfully bonded with the matrix material. Figure 2a-e portray the resultant microstructure images from the inverted microscope at the resolution of $200 \times$, which is the best suited and optimal resolution that justifies dispersion of all the incorporated reinforcement such as PFA and multi-wall carbon nanotubes. Furthermore, the uniform distribution of the synthesized composites can be witnessed from the grain boundaries formed in the microstructure images.

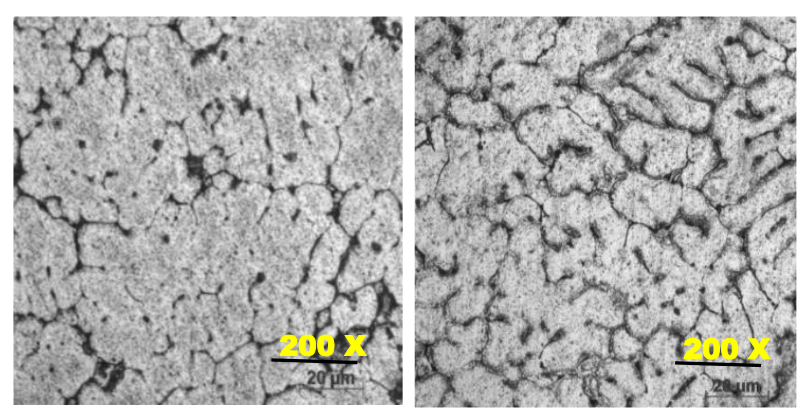

(a)

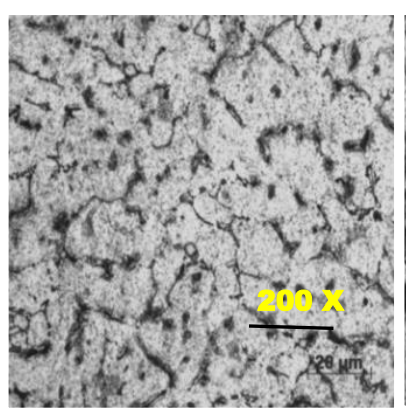

(c)

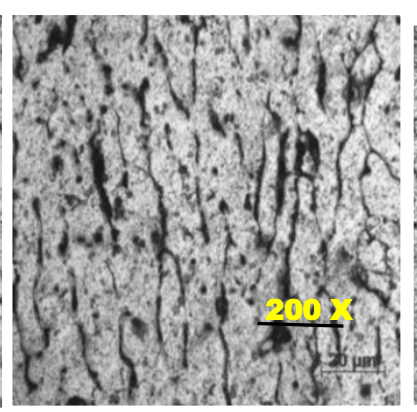

(d) (b)

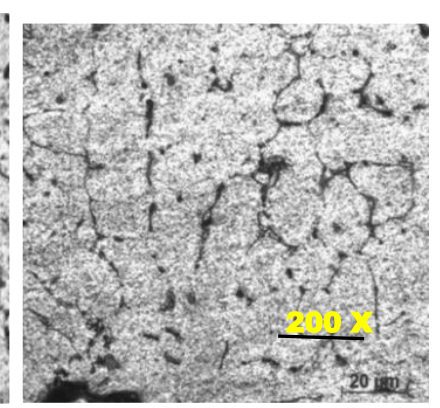

(e)

Figure 2. (a) Pure AA7075(200x); (b) AA7075 + 1\%(200×); (c) AA7075 + 2\%(200×); (d) AA7075 + $3 \%(200 \times)$; (e) AA7075 + 4\%(200×). 
The phase variations of the baste material that is Aluminium alloy of 7075 with the reinforcements such as MWCNTs and PFA are decipherable. The dispersed phase showing dotted sectors shows the base metal matrix, and the grain boundaries indicate the presence of the reinforcement. However, in our case, one of the reinforcements added is multi-wall carbon nanotubes, which are observed at the nano level, but microscopic studies show that the presence of this reinforcement. The other reinforcement of the hybrid metal matrix is PFA, which is characterized by low density, and volume is mixed with many foreign constituents such as $\mathrm{Al}_{2} \mathrm{O}_{3}, \mathrm{SiO}_{2}$, at a minimal level. Negligible quantities were infused within the base matrix, which is seen. Due to the high-temperature stir casting process, porosity and cracks can be seen in some parts of the composites. The floating and sinking were reduced in the composite structure because of the reinforcing particles. From this formation, after the solidification, MWCNTs and PFA were retained inside the composites. From Figure 2 of $3 \%$ and $4 \%$, it can be seen that the particles are aligned linearly, and increased agglomeration can be seen. The microstructure studies reveal the addition and the successful establishment of the desired levels at the highest possible standards of dispersion in the liquid metal matrix. Figure 3 gives the hardness results for five different compositions $(0,1,2,3,4)$, which were produced by adding MWCNTs and PFA. Figure 3 reveals that the hardness value of AA7075 reinforced with $4 \%$ MWCNTs and PFA was 133.2 VH, which was the highest. The hardness value of non-reinforced AA7075 was $117.5 \mathrm{VH}$ while the hardness of AA7075 reinforced with 1\% MWCNTs and PFA was $123.7 \mathrm{VH}$. The hardness value of $2 \%$ reinforced MMC was $123.7 \mathrm{VH}$. The hardness value of $3 \%$ reinforced MMC was $131.8 \mathrm{VH}$, and the hardness value for $4 \%$ was $133.2 \mathrm{VH}$. The hardness value shows a steady rise in increments of the reinforcement at wt. $\%$ of unity.

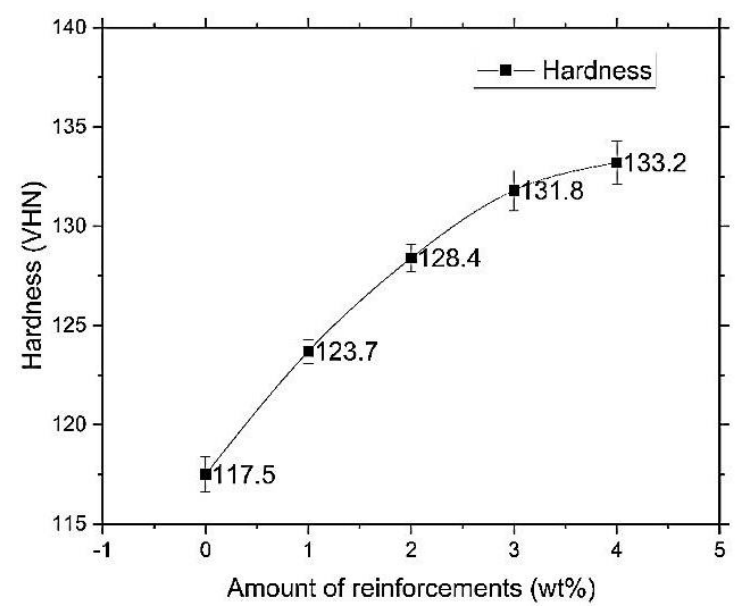

Figure 3. Amount of reinforcements (Wt.\%) vs. Hardness (HV).

Figure 4 gives the tensile strength value of five different compositions $(0,1,2,3,4)$, where the reinforcement particles added are MWCNTs and PFA. Tensile strength is one of the important parameters in mechanical properties. The tensile strength increases with an increase in reinforcement material $4 \%$. The maximum tensile strength is for $4 \%$, where the value is $165 \mathrm{MPa}$. The ultimate tensile strength for $0 \%, 1 \%, 2 \%, 3 \%$, and $4 \%$ are $80 \mathrm{MPa}, 112 \mathrm{MPa}, 136 \mathrm{MPa}, 152 \mathrm{Mpa}, 165 \mathrm{Mpa}$ respectively. The increase in tensile strength is due to the transmission of stress from the base metal to the reinforcement particles. It shows steady growth in the tensile strength from the non-reinforced base material to reinforced aluminium AA 7075, which indicates that the influence of the reinforcements such as MWCNTs and PFA had a tremendous effect on the tensile force of capability of the samples. 


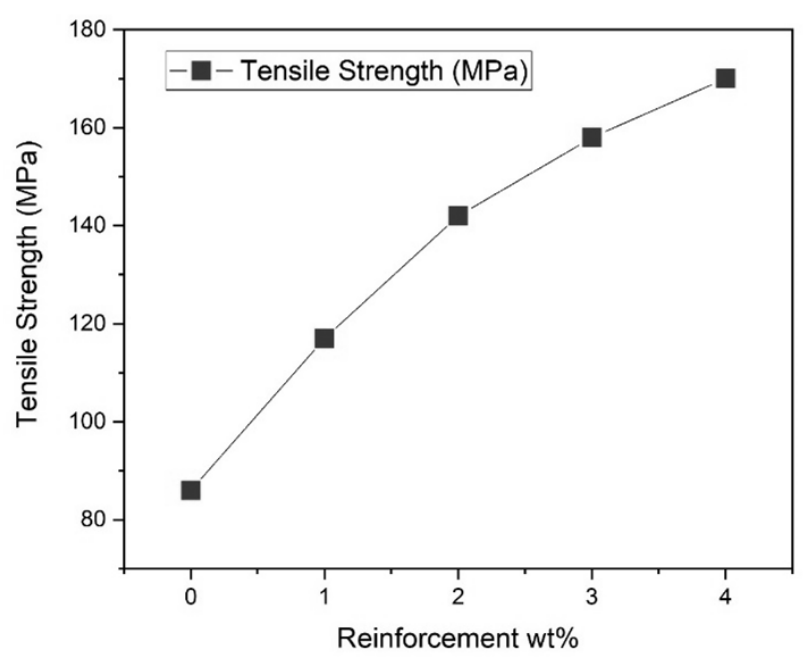

Figure 4. Amount of reinforcements (Wt.\%) vs. UTS (MPa).

The load capacities from the test that is the ultimate load-bearing capacity of aluminium alloy AA7075 is $1370 \mathrm{~N}$. The load capacities from the test that is the ultimate load-bearing capacity of aluminium alloy 7075 reinforced with $1 \%$ of MWCNTs and PFA is $2120 \mathrm{~N}$. The load capacity from the test that is the ultimate load-bearing capacity of aluminium alloy 7075 reinforced with $2 \%$ of MWCNTs and PFA is $3330 \mathrm{~N}$. The load capacity from the test that is the ultimate load-bearing capacity of aluminium alloy 7075 reinforced with $3 \%$ of MWCNTs and PFA is $4410 \mathrm{~N}$. The load capacity from the test that is the ultimate load-bearing capacity of aluminium alloy 7075 reinforced with $\%$ of MWCNTs and PFA is $5120 \mathrm{~N}$. Since both MWCNTs and PFA have brittle characteristics the ductility of the MMC is greatly reduced. With the increase in wt.\%, the grain size and homogenous microstructure are more refined, and it leads to superior wear resistance. The force bearing also increases upon the weight percentage of reinforcements in the metal matrix, which is a clear indication of the increase in the desired output.

\subsection{Wear Behavior}

Taguchi orthogonal array was chosen to determine the process variables of the input parameters, as Taguchi's method helps in the optimization of the response parameters concerning concerned factors. We have chosen various weight percentages such as level, and different input parameters such as load $(10,15,20,25,30) \mathrm{N}$, sliding speed $(250,300,350,400,450) \mathrm{rpm}$, sliding time $(5,7,9,11,13) \mathrm{min}$, composites $(0 \%, 1 \%, 2 \%, 3 \%, 4 \%)$ as factors. Using Minitab 18, we chose L 25 orthogonal array to find responses such as weight loss and wear rate. Taguchi helps in finding an overall best output parameter, as shown in Table 3, and plots are shown in Figure 5. 
Table 3. $\mathrm{L}_{25}$ array for weight loss and wear rate.

\begin{tabular}{ccccccc}
\hline Experiment & $\begin{array}{c}\text { Composites } \\
(\mathbf{w t} \text { \%) }\end{array}$ & $\begin{array}{c}\text { Load } \\
\mathbf{( N )}\end{array}$ & $\begin{array}{c}\text { Sliding } \\
\text { Speed } \\
\mathbf{( r p m )}\end{array}$ & $\begin{array}{c}\text { Sliding } \\
\text { Time } \\
(\mathbf{m i n})\end{array}$ & $\begin{array}{c}\text { Wear Rate } \\
(\mathbf{m m} \mathbf{3} / \mathbf{m})\end{array}$ & $\begin{array}{c}\text { Weight Loss } \\
(\mathbf{g})\end{array}$ \\
\hline 1 & 0 & 15 & 300 & 7 & 0.0056 & 0.0056 \\
2 & 0 & 10 & 250 & 5 & 0.0044 & 0.0044 \\
3 & 0 & 25 & 400 & 11 & 0.0067 & 0.0078 \\
4 & 0 & 20 & 350 & 9 & 0.0059 & 0.0059 \\
5 & 0 & 30 & 450 & 13 & 0.0083 & 0.0109 \\
6 & 1 & 20 & 400 & 13 & 0.0049 & 0.0044 \\
7 & 1 & 10 & 300 & 9 & 0.0034 & 0.0029 \\
8 & 1 & 30 & 250 & 7 & 0.0038 & 0.0034 \\
9 & 1 & 15 & 350 & 11 & 0.0045 & 0.0042 \\
10 & 1 & 25 & 450 & 5 & 0.0055 & 0.0055 \\
11 & 2 & 15 & 400 & 5 & 0.0030 & 0.0030 \\
12 & 2 & 10 & 350 & 13 & 0.0029 & 0.0029 \\
13 & 2 & 30 & 300 & 11 & 0.0032 & 0.0030 \\
14 & 2 & 20 & 450 & 7 & 0.0038 & 0.0038 \\
15 & 2 & 25 & 250 & 9 & 0.0024 & 0.0019 \\
16 & 3 & 15 & 450 & 9 & 0.0026 & 0.0022 \\
17 & 3 & 30 & 350 & 5 & 0.0014 & 0.0014 \\
18 & 3 & 25 & 300 & 13 & 0.0032 & 0.0032 \\
19 & 3 & 20 & 250 & 11 & 0.0021 & 0.0011 \\
20 & 3 & 10 & 400 & 7 & 0.0017 & 0.0016 \\
21 & 4 & 15 & 250 & 13 & 0.0014 & 0.0012 \\
22 & 4 & 10 & 450 & 11 & 0.0021 & 0.0017 \\
23 & 4 & 20 & 300 & 5 & 0.0009 & 0.0006 \\
24 & 4 & 350 & 400 & 9 & 0.0011 & 0.0009 \\
25 & 4 & 30 & & 0.0017 & 0.0013 \\
\hline
\end{tabular}

The analysis of variance is conducted with the Minitab statistical software to quantify the amount of percentage of contribution of each factor on the response, as shown in Table 4. The dominating influencing input process parameter is composites and wear rate and weight loss as response parameters. This marks a line that higher the addition of reinforcements, it owes to lesser wear rate and weight loss, thus by defining our objective. The ANOVA for wear rate and weight loss is shown in Table 5 . The full interaction plot shown in Figure 6 illustrates the various influences of input parameters on the output response.

Table 4. Analysis of Variance-Wear Rate.

\begin{tabular}{lcccccc}
\hline \multicolumn{7}{c}{ Analysis of Variance-Wear Rate } \\
\hline Source & DF & Adj SS & Adj MS & F-Value & $p$-Value & Percentage of contribution \\
Composites (wt. \%) & 4 & 0.000071 & 0.000018 & 170.87 & 0 & 82.55814 \\
Load (N) & 4 & 0.000002 & 0.000001 & 5.67 & 0.018 & 2.325581 \\
Sliding Speed (rpm) & 4 & 0.000008 & 0.000002 & 18.83 & 0 & 9.302326 \\
Sliding Time (min) & 4 & 0.000004 & 0.000001 & 10.16 & 0.003 & 4.651163 \\
Error & 8 & 0.000001 & $0 \mathrm{wt.} \%$ & - & - & 1.162791 \\
Total & 24 & 0.000086 & - & - & - & 100.0000 \\
\hline
\end{tabular}




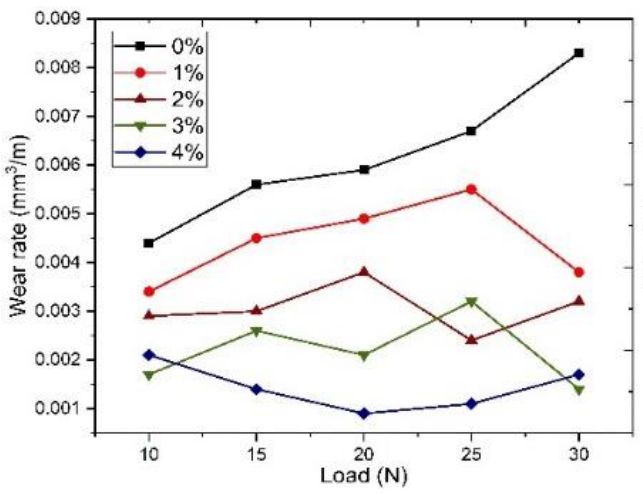

(a)

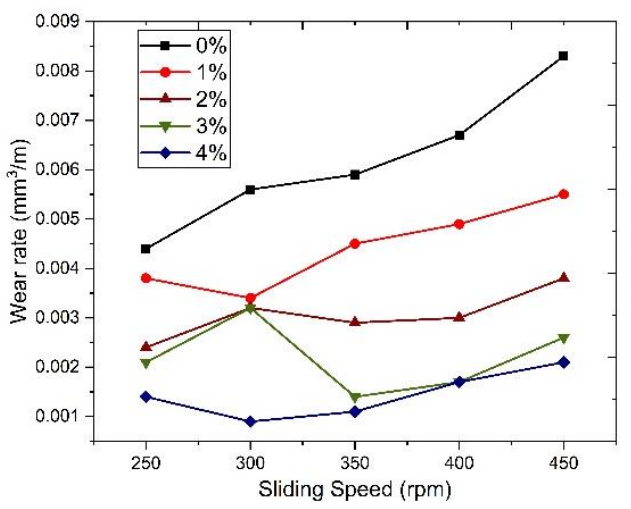

(c)

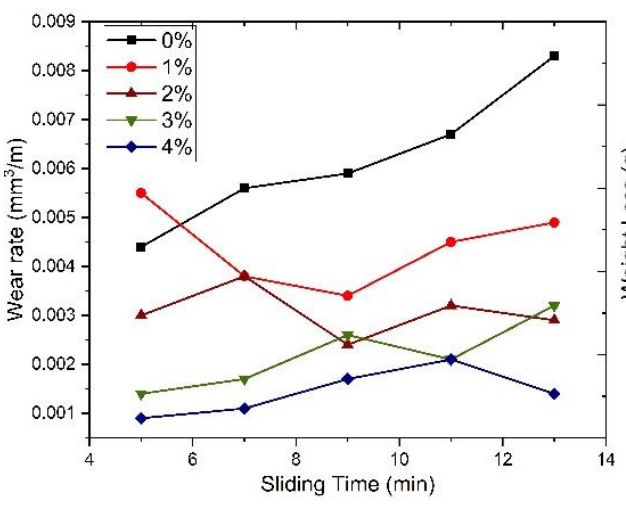

(e)

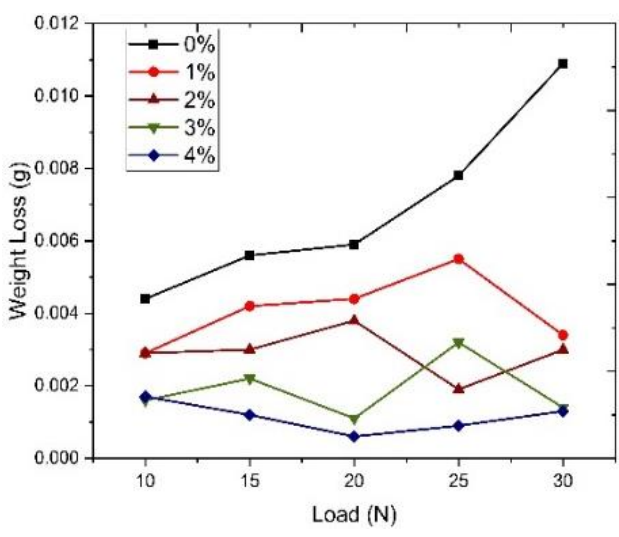

(b)

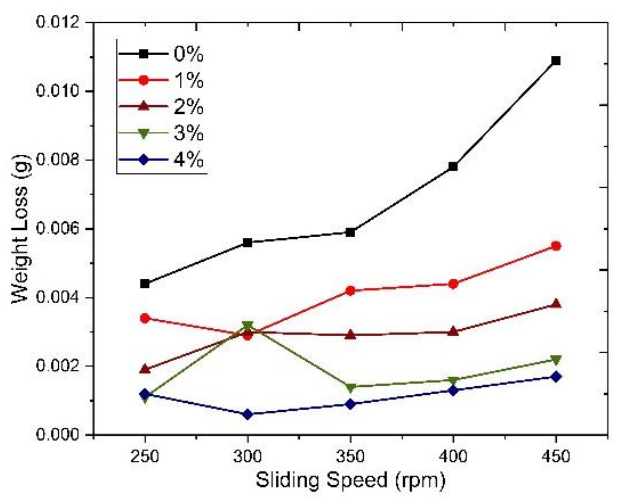

(d)

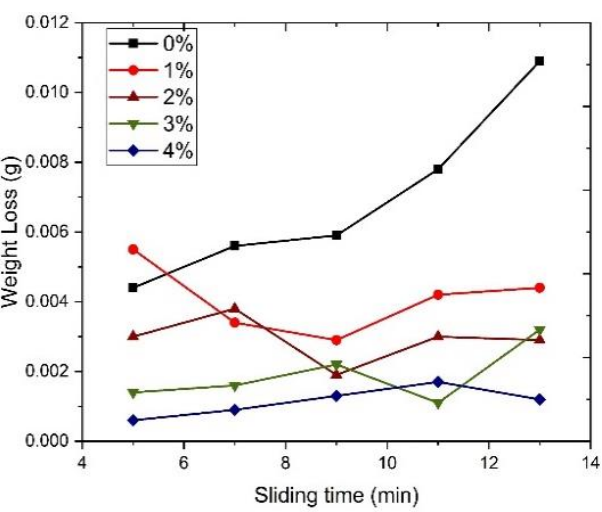

(f)

Figure 5. Removal rate and weight loss response according to load, sliding speed and sliding time. $(\mathbf{a}, \mathbf{b})$ can be witnessed that in most cases, the wear rate and weight loss decreases, with a corresponding increase in the composites (wt.\%), also taking into account the different values of load (N); (c,d) can be observed that in most cases, the wear rate and weight loss decreases, with a corresponding increase in the composites (wt.\%), also taking into account the different values of sliding speed (rpm); (e,f) can be perceived that in most cases, the wear rate and weight loss decreases, with a corresponding increase in the composites (wt.\%), also taking into account the different values of sliding time (minutes). 
Table 5. Analysis of Variance-Weight loss.

\begin{tabular}{lcccccc}
\hline \multicolumn{7}{c}{ Analysis of Variance-Weight Loss } \\
\hline Source & DF & Adj SS & Adj MS & F-Value & $p$-Value & Percentage of contribution \\
Composites (wt.\%) & 4 & 0.0001 & 0.000025 & 52.5 & 0 & 72.9927 \\
Load (N) & 4 & 0.000006 & 0.000001 & 2.91 & 0.093 & 4.379562 \\
Sliding speed (rpm) & 4 & 0.000015 & 0.000004 & 7.98 & 0.007 & 10.94891 \\
Sliding time (min) & 4 & 0.000009 & 0.000002 & 4.74 & 0.03 & 6.569343 \\
Error & 8 & 0.000004 & 0 & - & - & 2.919708 \\
Total & 24 & 0.000137 & - & - & - & 100.0000 \\
\hline
\end{tabular}

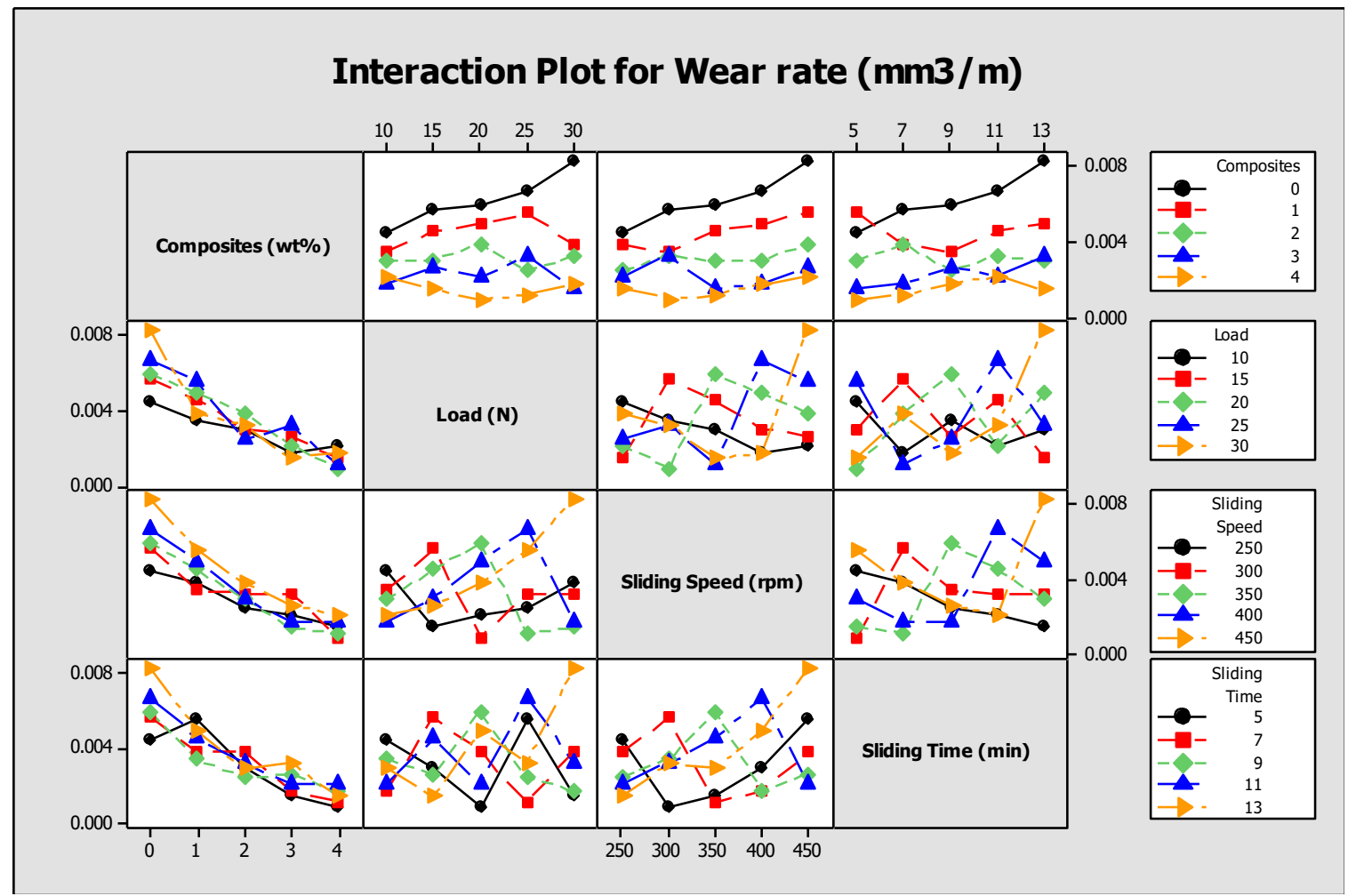

Figure 6. Interaction plot for wear rate.

The main effects plot and signal to noise ratio are shown in Figures 7-10 for wear rate and weight loss, as well as response tables for means and $\mathrm{S} / \mathrm{N}$ ratio in Tables 6-9. The smaller condition is chosen as the Taguchi objective, as we need minimal wear rate and weight loss. Figures 7-10 state that composite is the most influencing parameter on the output parameter, thereby validating our objective for the addition of reinforcements to enhance the wear behavior of the hybrid metal matrix composites. In the mean of signal to noise ratio represented in Figure 8, from the observation composite, weight increases towards the frictional behavior of Al7075. Load influence is negligible, whereas sliding time and speed partially influence the wear rate. In the aspect of weight loss, which is shown in Figure 9, the effect of composite, load, sliding time, and speed contributed similarly to the wear rate. In Figure 10, the curve trend concerning weight loss indicates the addition of composites for enhancing the wear resistance. With respect to load, wear loss increased proportionally, and by following the same drift, weight loss increased with increment in sliding speed and time. 
Table 6. Response Table for $\mathrm{S} / \mathrm{N}$ ratio (Wear rate).

\begin{tabular}{ccccc}
\hline Level & Composites (wt. $\%)$ & Load (N) & Sliding Speed (rpm) & Sliding Time (min) \\
\hline 1 & 44.37 & 51.24 & 51.71 & 52.15 \\
2 & 47.22 & 50.24 & 51.02 & 51.28 \\
3 & 50.38 & 50.73 & 51.70 & 50.69 \\
4 & 53.52 & 50.03 & 50.18 & 49.48 \\
5 & 57.22 & 50.48 & 48.09 & 49.11 \\
Delta & 12.85 & 1.21 & 3.62 & 3.05 \\
Rank & 1 & 4 & 2 & 3 \\
\hline
\end{tabular}

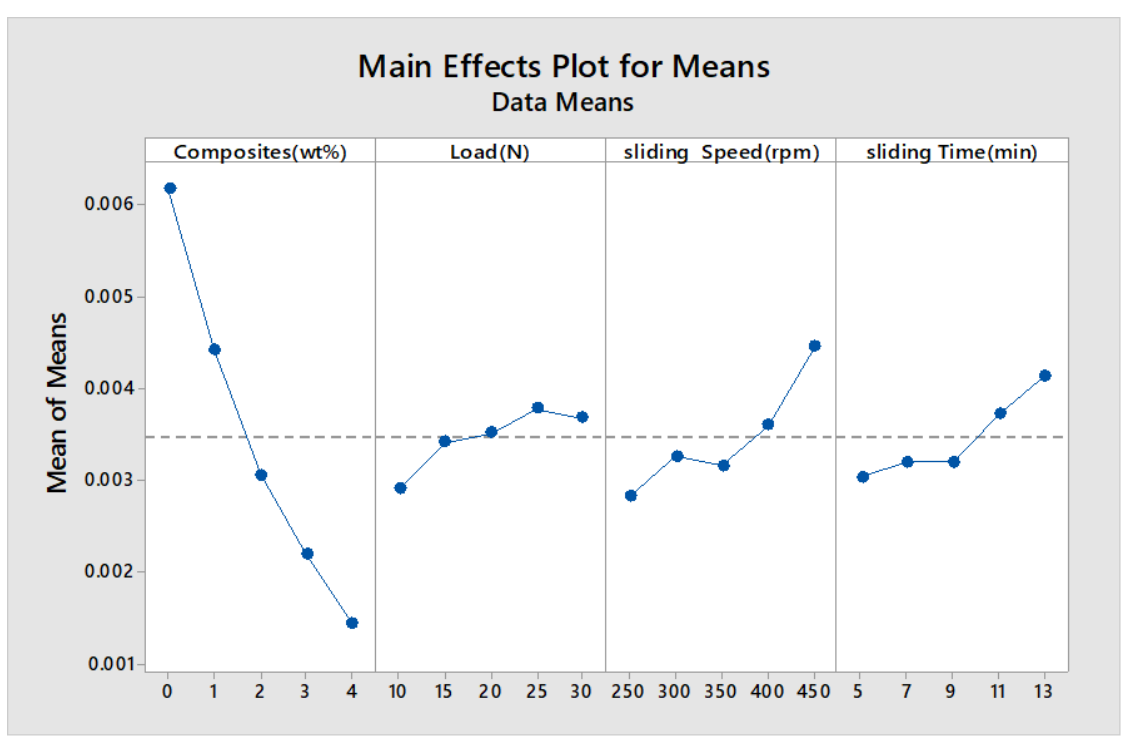

Figure 7. Main effects plot (Wear rate).

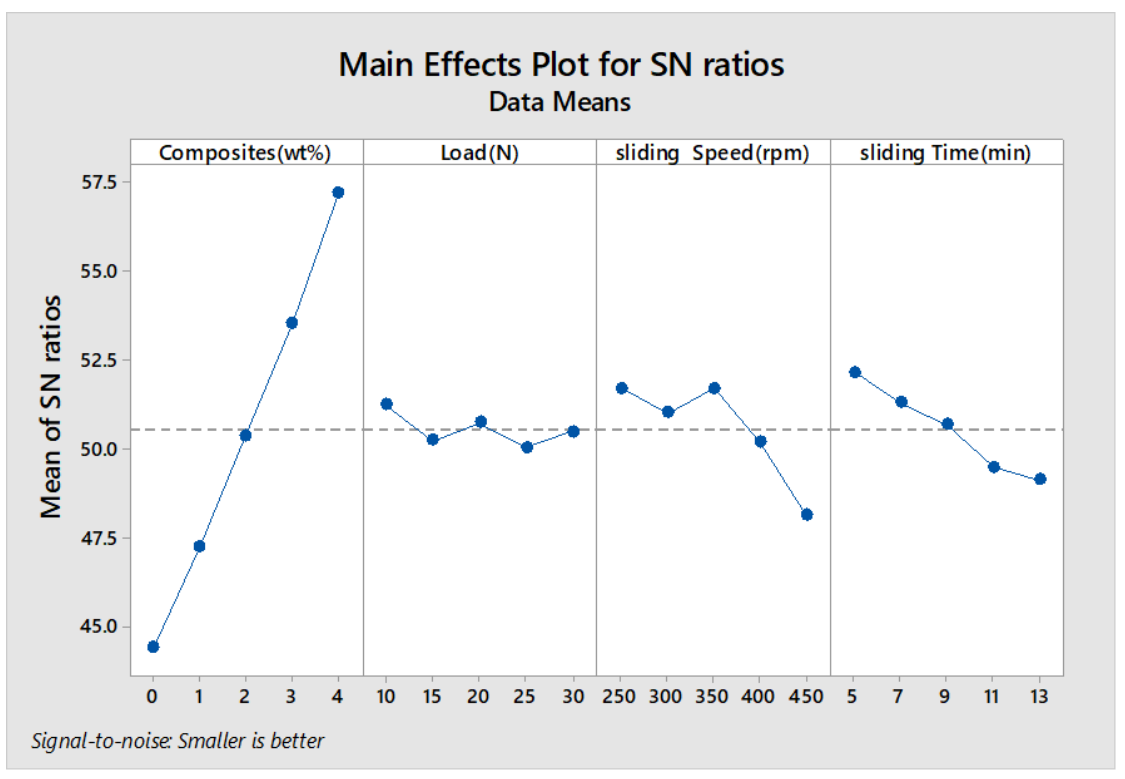

Figure 8. S/N Ratio plot (Wear rate). 


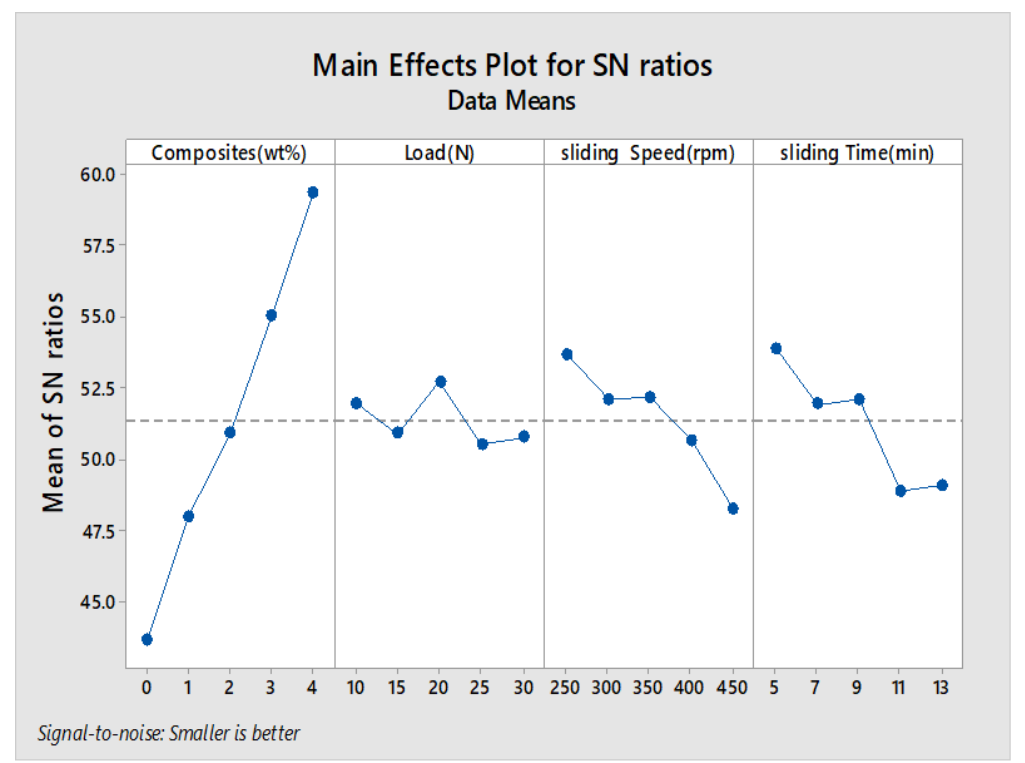

Figure 9. Main effects plot (weight loss).

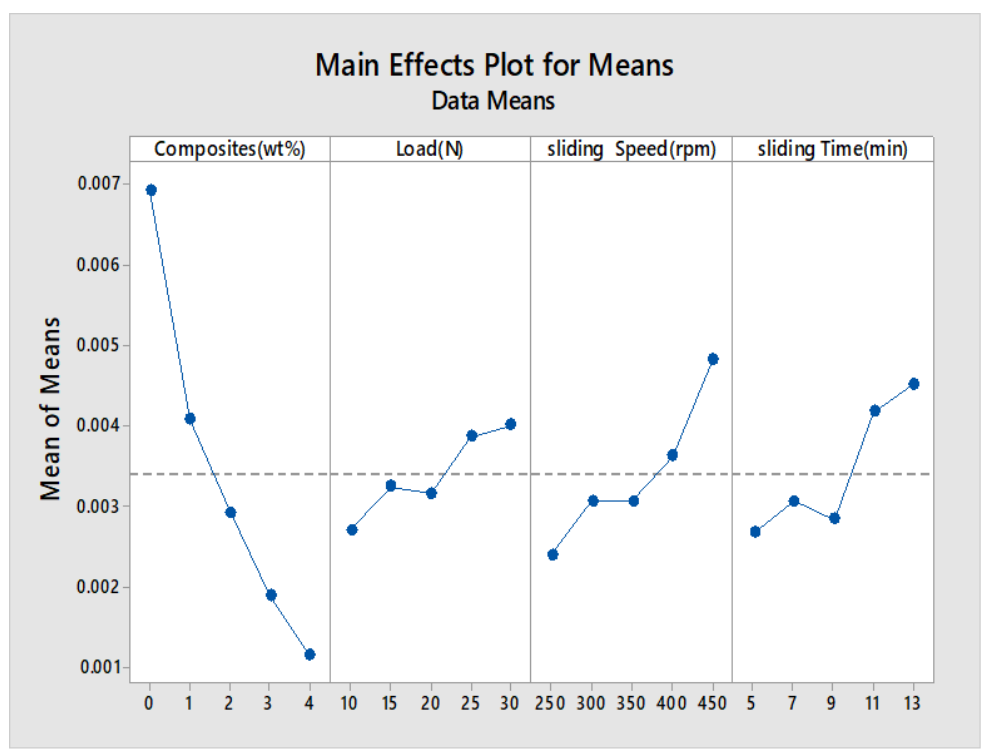

Figure 10. S/N Ratio plot (Weight loss).

Table 7. Response Table for Means (Wear rate).

\begin{tabular}{ccccc}
\hline Level & Composites (wt.\%) & Load (N) & Sliding Speed (rpm) & Sliding Time (min) \\
\hline 1 & 0.006180 & 0.002900 & 0.002820 & 0.003040 \\
2 & 0.004420 & 0.003420 & 0.003260 & 0.003200 \\
3 & 0.003060 & 0.003520 & 0.003160 & 0.003200 \\
4 & 0.002200 & 0.003780 & 0.003600 & 0.003720 \\
5 & 0.001440 & 0.003680 & 0.004460 & 0.004140 \\
Delta & 0.004740 & 0.000880 & 0.001640 & 0.001100 \\
Rank & 1 & 4 & 2 & 3 \\
\hline
\end{tabular}


Table 8. Response Table for Means (Weight loss).

\begin{tabular}{ccccc}
\hline Level & Composites (wt. $\%)$ & Load $(\mathbf{N})$ & Sliding Speed (rpm) & Sliding Time (min) \\
\hline 1 & 0.006920 & 0.002700 & 0.002400 & 0.002667 \\
2 & 0.004080 & 0.003240 & 0.003060 & 0.003060 \\
3 & 0.002920 & 0.003160 & 0.003060 & 0.002840 \\
4 & 0.001900 & 0.003860 & 0.003620 & 0.004175 \\
5 & 0.001140 & 0.004000 & 0.004820 & 0.004520 \\
Delta & 0.005780 & 0.001300 & 0.002420 & 0.001853 \\
Rank & 1 & 4 & 2 & 3 \\
\hline
\end{tabular}

Table 9. Response Table for $\mathrm{S} / \mathrm{N}$ ratio (Weight loss).

\begin{tabular}{ccccc}
\hline Level & Composites (wt. $\%)$ & Load (N) & Speed (rpm) & Time (min) \\
\hline 1 & 43.63 & 51.99 & 53.70 & 53.91 \\
2 & 48.00 & 50.92 & 52.12 & 51.93 \\
3 & 50.90 & 52.75 & 52.17 & 52.13 \\
4 & 55.04 & 50.52 & 50.68 & 48.89 \\
5 & 59.38 & 50.78 & 48.28 & 49.09 \\
Delta & 15.74 & 2.23 & 5.42 & 5.03 \\
Rank & 1 & 4 & 2 & 3 \\
\hline
\end{tabular}

The Genetic Algorithm is one most sophisticated optimization tools implemented with the help of MATLAB. Moreover, the fitness function is generated from the regression equation in Minitab and the number of variables indicating the input process parameters to get the best and mean result of the output response along with corresponding input parameters. The upper and lower bounds of the population are given for better-optimized results. The experimental results were used for finding the wear rate with the help of Taguchi's orthogonal array, and the regression equation is created in Minitab. The fitness function shown in Equation (1) is derived from regression equations and given as input along with the input process variables to the GA optimization tool, as shown in Figure 11.

$$
\begin{aligned}
\text { Fitness function } & =@(x)+0.001274-0.001170 \cdot x(1) \\
& +0.000038 \cdot x(2)+0.000007 \cdot x(3)+0.000136 \cdot x(4)
\end{aligned}
$$

After solving, GA provides the best input as composites (4\%), load (10 N), sliding speed (250 rpm), and sliding time ( $5 \mathrm{~min}$ ), and the best wear rate as 0.0005955 . The experiment is carried with the above input, and the wear rate was found to be 0.000624521 , indicating the validation of GA results. Shown in Table 10.

Table 10. Comparison of optimized results-Wear rate.

\begin{tabular}{cccccc}
\hline Methods & $\begin{array}{c}\text { Composites } \\
(\mathbf{w t .} \%)\end{array}$ & $\begin{array}{c}\text { Load } \\
\mathbf{( N )}\end{array}$ & $\begin{array}{c}\text { Sliding Speed } \\
\mathbf{( r p m )}\end{array}$ & $\begin{array}{c}\text { Sliding Time } \\
(\mathbf{m i n})\end{array}$ & $\begin{array}{c}\text { Wear Rate } \\
\left(\mathbf{m m}^{\mathbf{3}} \mathbf{/ m}\right)\end{array}$ \\
\hline GA results & 4 & 10 & 250 & 5 & 0.0005955 \\
Experiment results & 4 & 10 & 250 & 5 & 0.000624521 \\
\hline
\end{tabular}



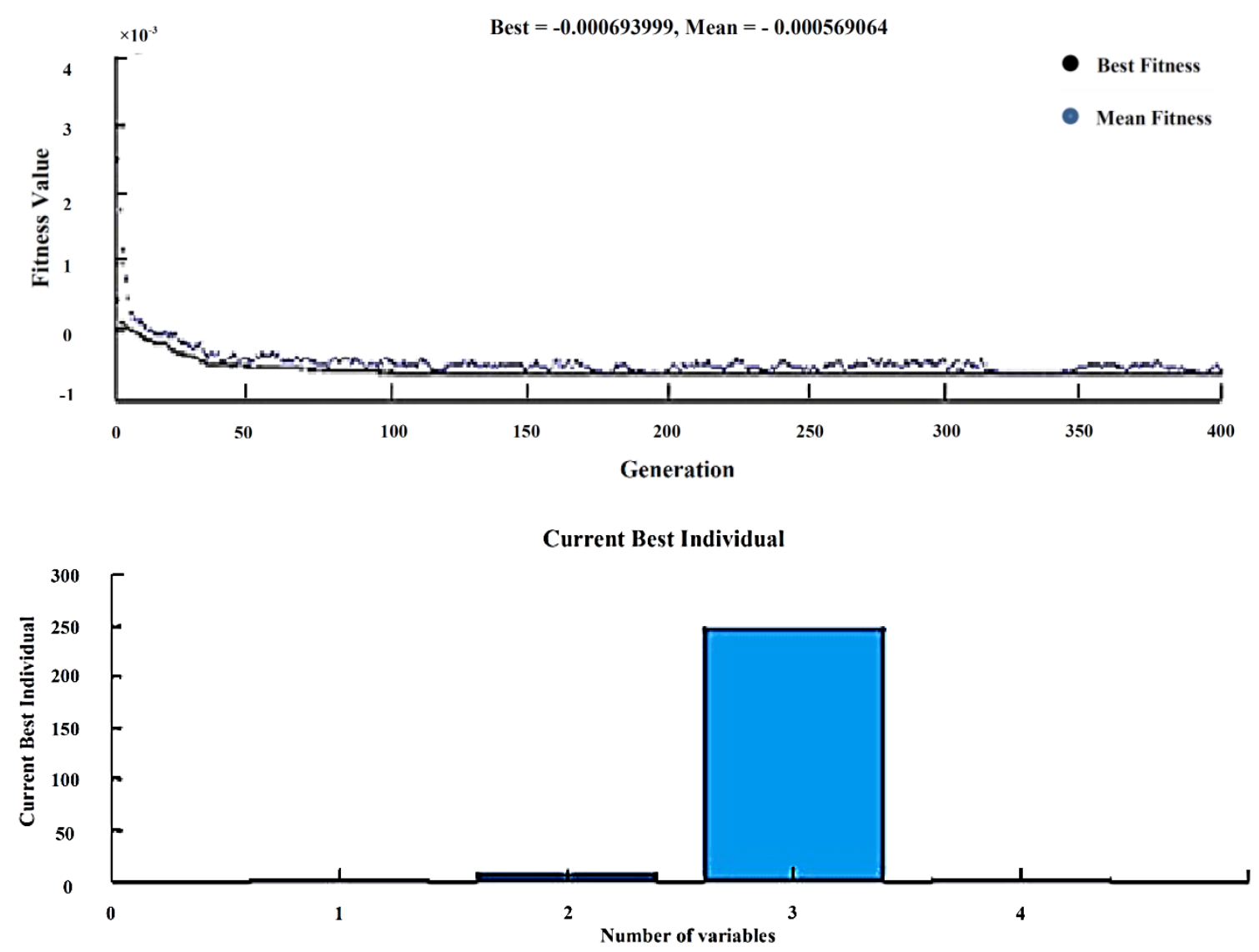

Figure 11. Best and Mean results-Wear rate.

\subsection{Analysis of Weight Loss}

The above procedure was carried out for finding weight loss with the help of Taguchi's orthogonal array, and the regression equation is created in Minitab. Fitness function shown in Equation (2), is derived from regression equations and given as input along with the input process variables to the GA optimization tool, as shown in Figure 12.

$$
\begin{aligned}
\text { Fitness function } & =@(x)+0.00016-0.001354 \cdot x(1) \\
& +0.000064 \cdot x(2)+0.000010 \cdot x(3)+0.000168 \cdot x(4)
\end{aligned}
$$

After solving, GA provides the best input as composites (4\%), load (10 N), sliding speed (250 rpm), and sliding time (5 $\mathrm{min}$ ), and the best weight loss as 0.001276 . The experiment is carried with the above input, and the wear rate was found to be 0.0014231 , indicating the validation of GA results, as shown in Table 11.

Table 11. Comparison of optimized results-Weight loss.

\begin{tabular}{cccccc}
\hline Methods & $\begin{array}{c}\text { Composites } \\
\text { (wt.\%) }\end{array}$ & $\begin{array}{c}\text { Load } \\
\mathbf{( N )}\end{array}$ & $\begin{array}{c}\text { Sliding Speed } \\
(\mathbf{r p m})\end{array}$ & $\begin{array}{c}\text { Sliding Time } \\
\text { (min) }\end{array}$ & $\begin{array}{c}\text { Weight Loss } \\
(\mathbf{g})\end{array}$ \\
\hline GA results & 4 & 10 & 250 & 5 & 0.001276 \\
Experiment results & 4 & 10 & 250 & 5 & 0.0014231 \\
\hline
\end{tabular}




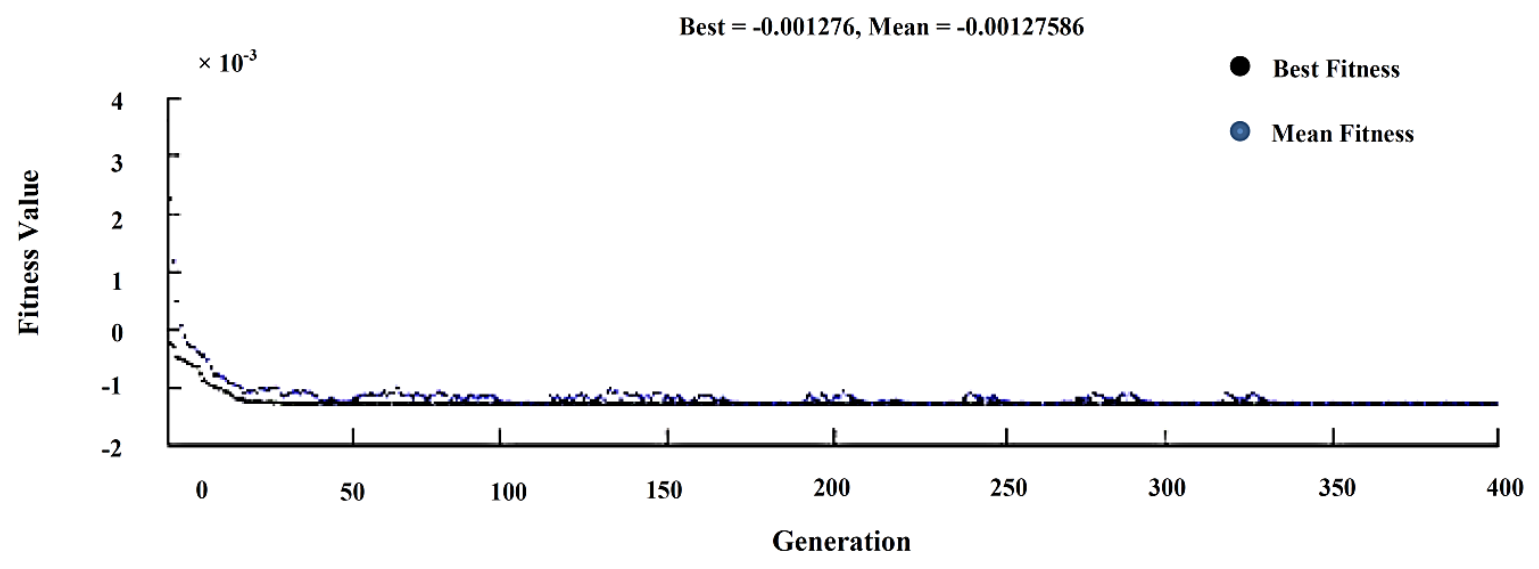

Current Best Individual

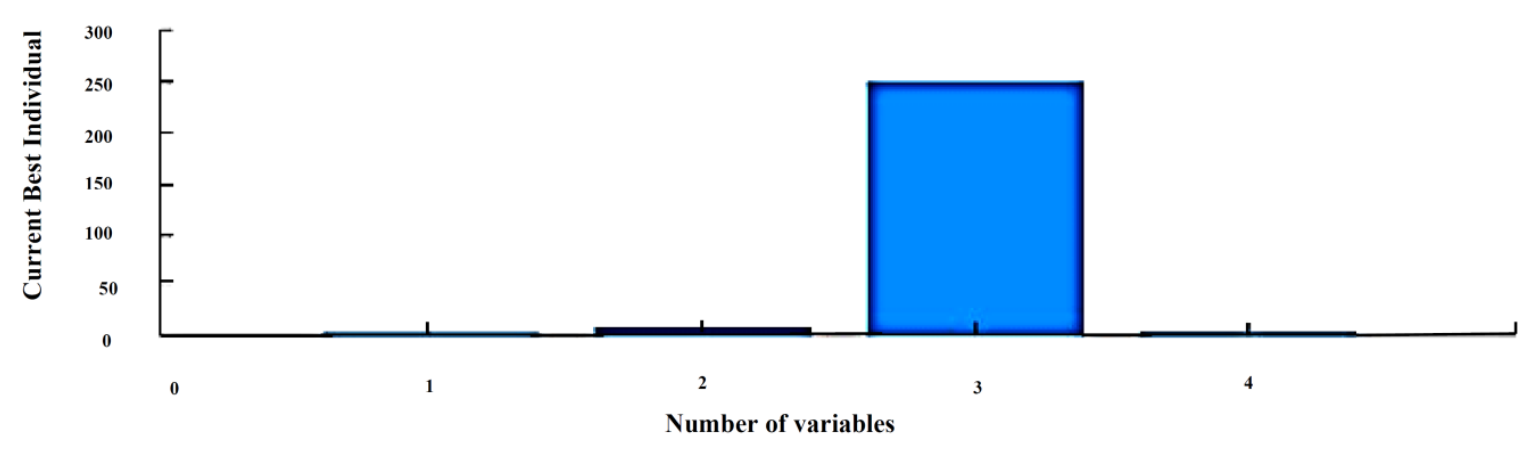

Figure 12. Best and Mean results-Weight loss.

\subsection{Wire Cut-EDM}

Similar to the wear rate and weight loss Taguchi method, material removal rate was determined through wire EDM, with input parameters such as composites, pulse off, pulse on, and peak current as factors and various weight percentages as level. Minitab, a statistical analysis software, chooses the best $\mathrm{L}_{25}$ orthogonal array. Factors such as composites $(0 \%, 1 \%, 2 \%, 3 \%, 4 \%)$, pulse on $(12,24,36,48,60)$ $\mu \mathrm{S}$, pulse off $(4,5,6,7,8) \mu \mathrm{S}$, and current as $(1,2,3,4,5) \mathrm{A}$ are the input parameters, and MRR is the output parameter, as shown in Table 12, and the plotted graph is illustrated in Figure 13.

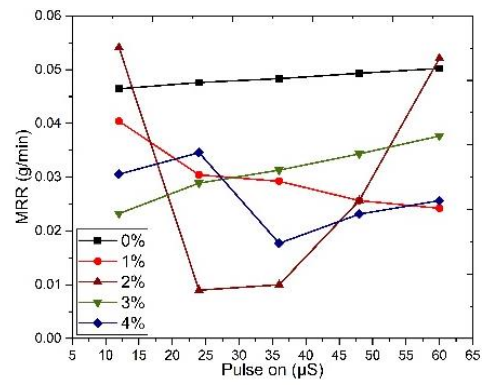

(a)

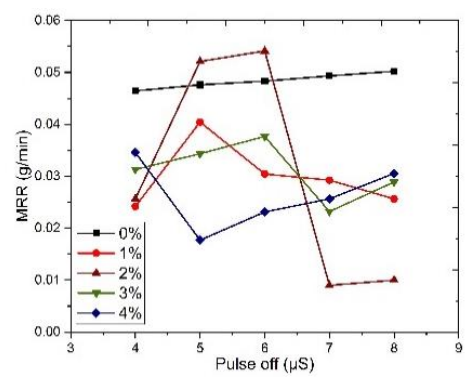

(b)

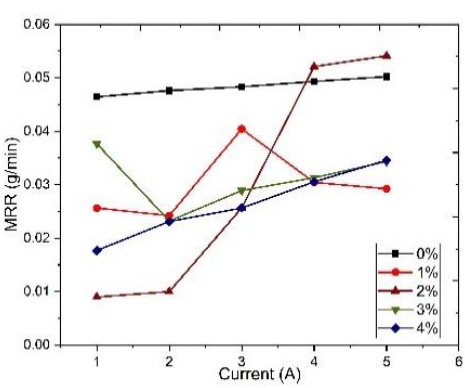

(c)

Figure 13. Material removal rate response according to Pulse and Current: (a) pulse on; (b) pulse off; (c) current.

As the same procedure followed for wear rate and weight loss, the percentage of contribution was found for input parameters such as composites, pulse off, pulse on, current to corresponding response parameters such as material removal rate and interaction plot, as shown in Figure 14. Table 13 explains 
that the higher the addition of reinforcements, the less the material removal rate. A full interaction plot also helps in easy visualization of the impact of the influencing parameters.

Table 12. $\mathrm{L}_{25}$ array for Material Removal Rate.

\begin{tabular}{|c|c|c|c|c|c|}
\hline Exp. No. & Composites (Wt \%) & Pulse On $(\mu s)$ & Pulse Off $(\mu s)$ & Current (A) & $\operatorname{MRR}(\mathrm{g} / \mathrm{min})$ \\
\hline 1 & 0 & 12 & 4 & 1 & 0.0464300 \\
\hline 2 & 0 & 24 & 5 & 2 & 0.0476000 \\
\hline 3 & 0 & 4 & 6 & 3 & 0.0483200 \\
\hline 4 & 0 & 5 & 7 & 4 & 0.0493200 \\
\hline 5 & 0 & 6 & 8 & 5 & 0.0502123 \\
\hline 6 & 1 & 7 & 5 & 3 & 0.0404200 \\
\hline 7 & 1 & 8 & 6 & 4 & 0.0304210 \\
\hline 8 & 1 & 36 & 7 & 5 & 0.0292321 \\
\hline 9 & 1 & 48 & 8 & 1 & 0.0256421 \\
\hline 10 & 1 & 60 & 4 & 2 & 0.0242123 \\
\hline 11 & 2 & 12 & 6 & 5 & 0.0541325 \\
\hline 12 & 2 & 24 & 7 & 1 & 0.0089766 \\
\hline 13 & 2 & 36 & 8 & 2 & 0.0099765 \\
\hline 14 & 2 & 48 & 4 & 3 & 0.0256521 \\
\hline 15 & 2 & 60 & 5 & 4 & 0.0521110 \\
\hline 16 & 3 & 12 & 7 & 2 & 0.0232123 \\
\hline 17 & 3 & 24 & 8 & 3 & 0.0288970 \\
\hline 18 & 3 & 36 & 4 & 4 & 0.0313130 \\
\hline 19 & 3 & 48 & 5 & 5 & 0.0343210 \\
\hline 20 & 3 & 60 & 6 & 1 & 0.0376500 \\
\hline 21 & 4 & 12 & 8 & 4 & 0.0305421 \\
\hline 22 & 4 & 24 & 4 & 5 & 0.0345600 \\
\hline 23 & 4 & 36 & 5 & 1 & 0.0176932 \\
\hline 24 & 4 & 48 & 6 & 2 & 0.0231234 \\
\hline 25 & 4 & 60 & 7 & 3 & 0.0256422 \\
\hline
\end{tabular}

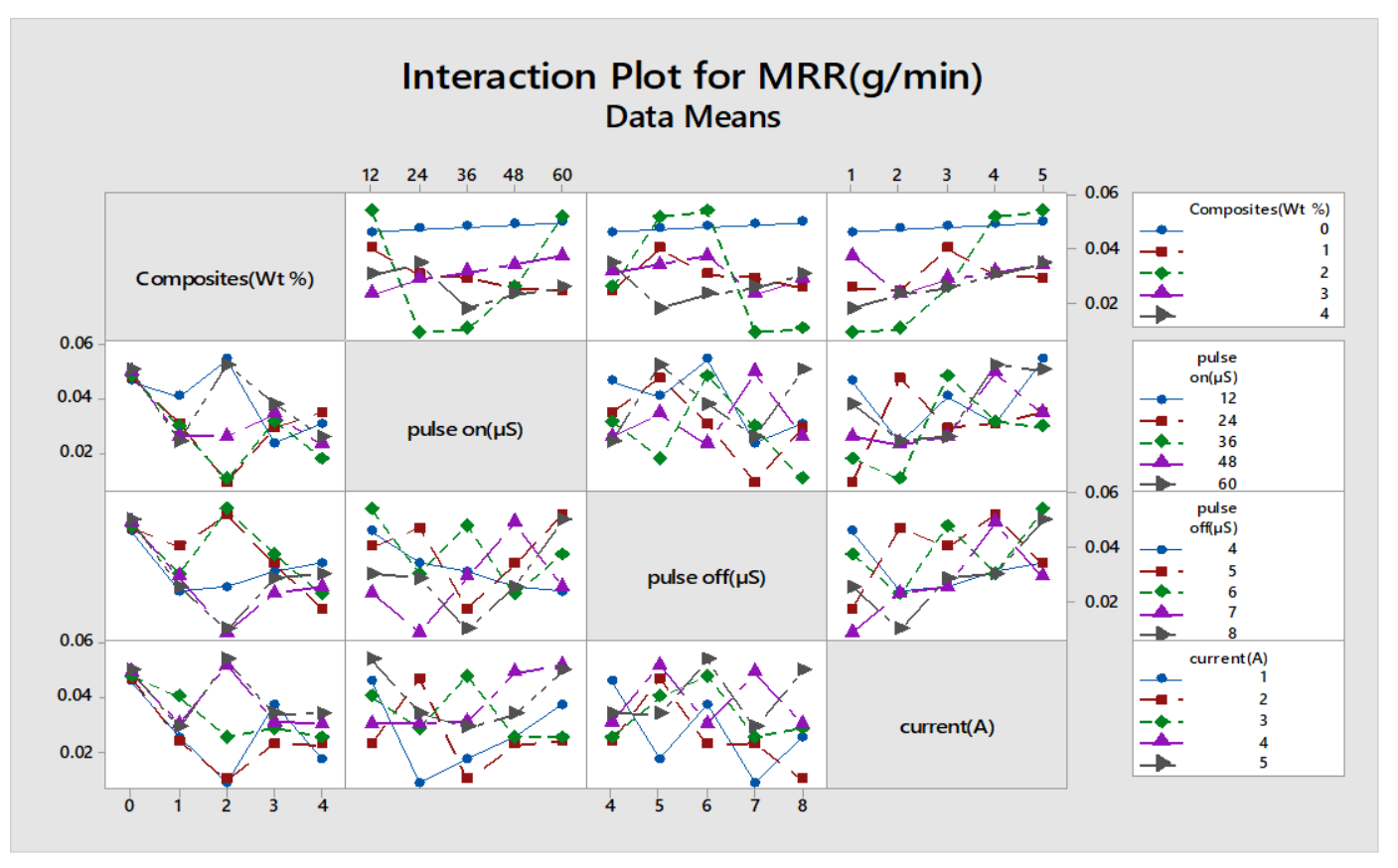

Figure 14. Interaction plot for MRR. 
Table 13. Analysis of Variance-MRR.

\begin{tabular}{ccccccc}
\hline \multicolumn{7}{c}{ Analysis of Variance } \\
\hline Source & DF & Adj SS & Adj MS & F-Value & $p$-Value & Percent of Contribution \\
Composites $(\mathrm{Wt} . \%)$ & 4 & 0.001509 & 0.000377 & 6.79 & 0.011 & 38.65266 \\
Pulse On $(\mu \mathrm{S})$ & 4 & 0.000513 & 0.000128 & 2.31 & 0.146 & 13.14037 \\
Pulse Off( $\mu \mathrm{S})$ & 4 & 0.000554 & 0.000138 & 2.49 & 0.126 & 14.19057 \\
Current $(\mathrm{A})$ & 4 & 0.000883 & 0.000221 & 3.98 & 0.046 & 22.61783 \\
Error & 8 & 0.000444 & 0.000056 & - & - & 11.37295 \\
Total & 24 & 0.003904 & - & - & - & 100.0000 \\
\hline
\end{tabular}

The Minitab statistical software was used to determine the most influencing input factors that affect the responses. Furthermore, this gives a detailed ranking of the influencing parameters. The smaller condition is chosen for wear rate and weight loss, whereas for material removal rate, the better is selected for determining the machining capability of the material. The main effects plot and $S / N$ ratio plot are shown in Figures 15 and 16. The response table for means and $\mathrm{S} / \mathrm{N}$ are shown in Tables 14 and 15.

Table 14. Response Table for Means (MRR).

\begin{tabular}{ccccc}
\hline Level & Composites $(w t . \%)$ & Pulse ON $(\mu \mathrm{S})$ & Pulse OFF $(\mu \mathrm{S})$ & Current $(\mathrm{A})$ \\
\hline 1 & 0.04838 & 0.03895 & 0.03243 & 0.02728 \\
2 & 0.02999 & 0.03009 & 0.03843 & 0.02562 \\
3 & 0.03017 & 0.02731 & 0.03873 & 0.03379 \\
4 & 0.03108 & 0.03161 & 0.02728 & 0.03874 \\
5 & 0.02631 & 0.03797 & 0.02905 & 0.04049 \\
Delta & 0.02206 & 0.01164 & 0.01145 & 0.01487 \\
Rank & 1 & 3 & 4 & 2 \\
\hline
\end{tabular}

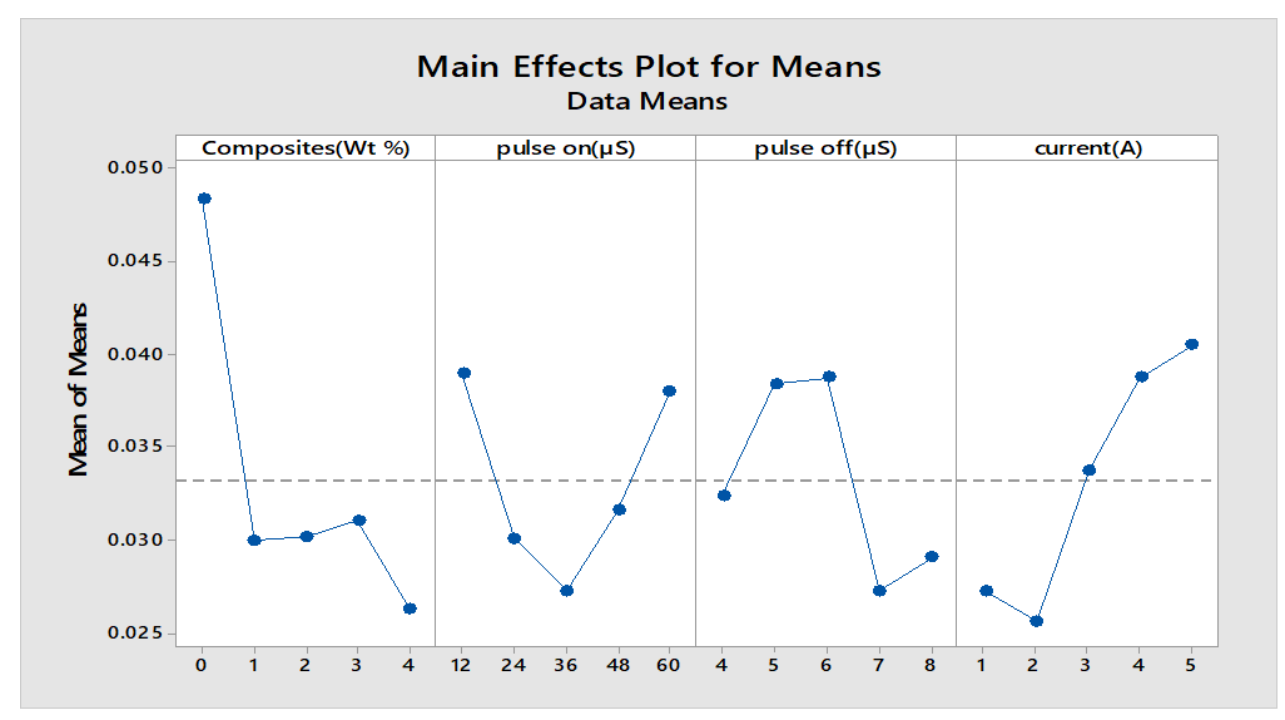

Figure 15. Main effects plot for MRR. 


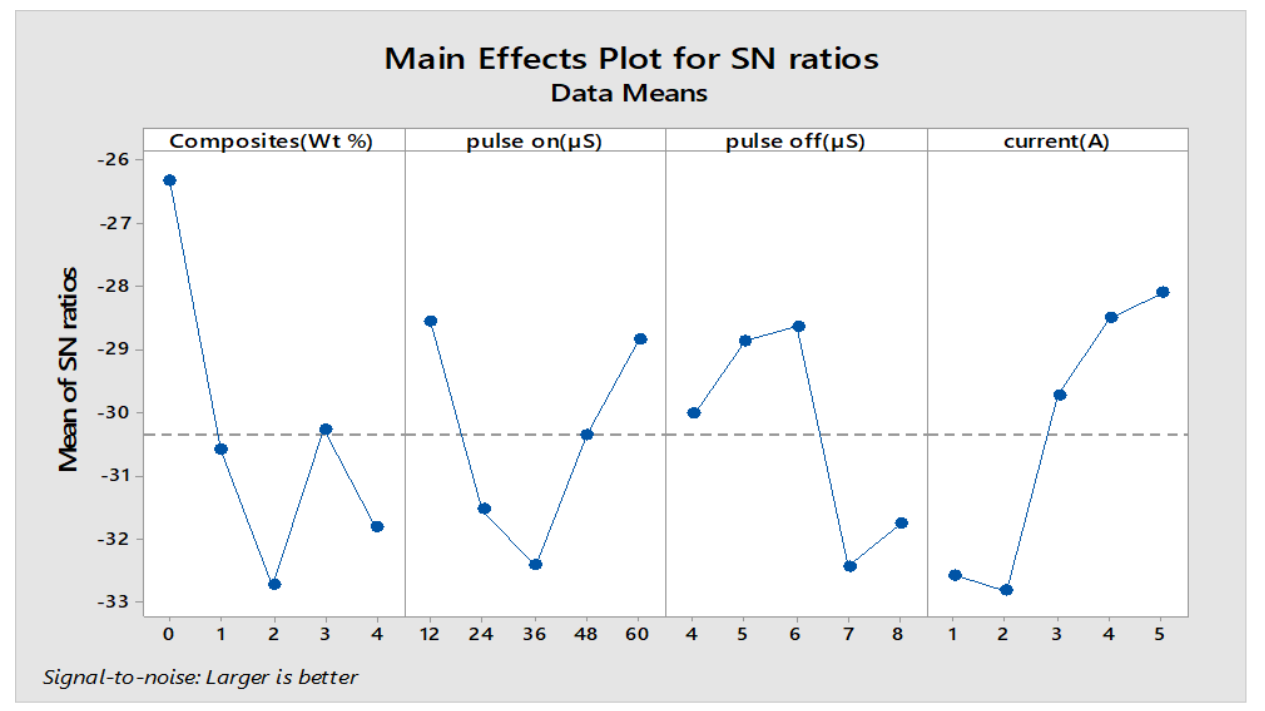

Figure 16. S/N Ratio plot for MRR.

Table 15. Response Table for $\mathrm{S} / \mathrm{N}$ ratio (MRR).

\begin{tabular}{ccccc}
\hline Level & Composites $(w t . \%)$ & Pulse ON $(\mu \mathrm{S})$ & Pulse OFF $(\boldsymbol{\mu S})$ & Current $(\mathrm{A})$ \\
\hline 1 & -26.31 & -28.57 & -30.02 & -32.59 \\
2 & -30.61 & -31.55 & -28.86 & -32.84 \\
3 & -32.75 & -32.43 & -28.64 & -29.72 \\
4 & -30.27 & -30.36 & -32.45 & -28.51 \\
5 & -31.82 & -28.85 & -31.78 & -28.10 \\
Delta & 6.44 & 3.86 & 3.82 & 4.74 \\
Rank & 1 & 3 & 4 & 2 \\
\hline
\end{tabular}

Table 14 infers that the composites are given a higher rank of influencing variables, and this clearly explains the impact of various weight percentages of reinforcements contributing to MRR. The addition of reinforcements reduces the MRR, as it increases the hardness and mechanical strength of that MMC, owing to much less machining capability. The experimental results were deployed for finding MRR with the help of Taguchi's orthogonal array; the regression equation is created in Minitab. The fitness function shown in Equation (3) is derived from regression equations and given as input along with the input process variables to the GA optimization tool.

$$
\begin{aligned}
\text { Fitness function } & =@(x)+0.0408-0.00430 \cdot x(1) \\
& -0.000004 \cdot x(2)-0.00179 \cdot x(3)-0.00395 \cdot x(4)
\end{aligned}
$$

The GA provides the best input values along with the corresponding MRR best and means values shown in Figure 17. An experiment is carried for that particular input combination, and it is clear that both the GA and experimental results are in closed accuracy, as shown in Table 16. 
Best $=0.01299$, Mean $=0.0129901$

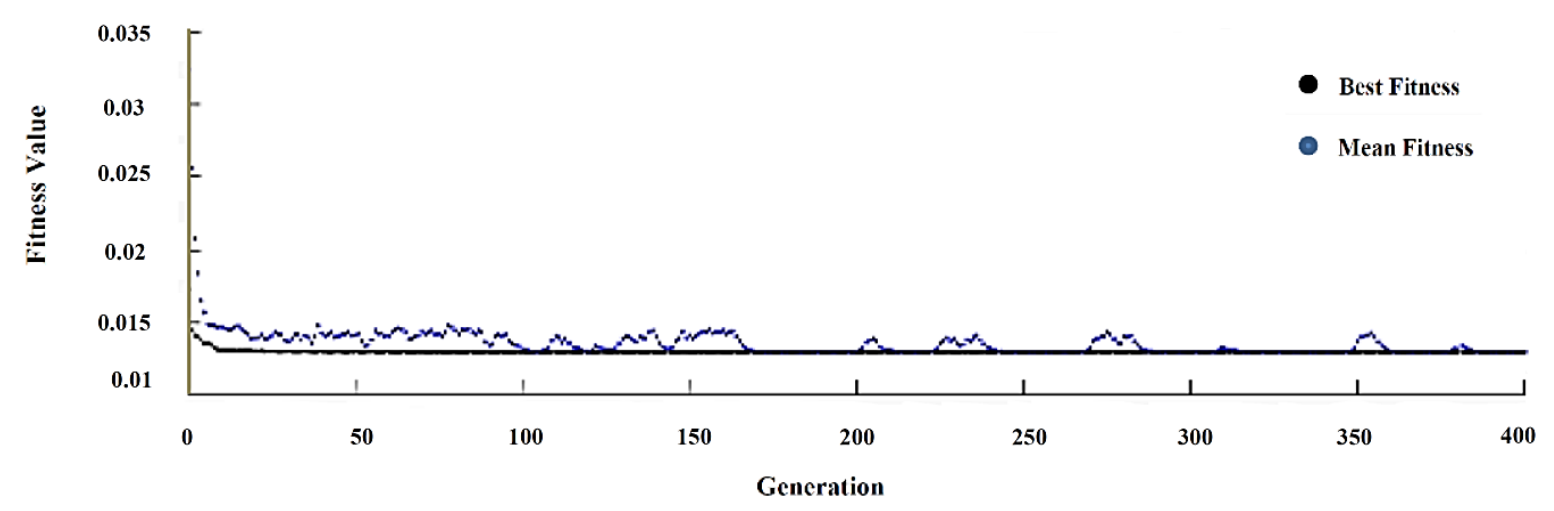

Current Best Individual

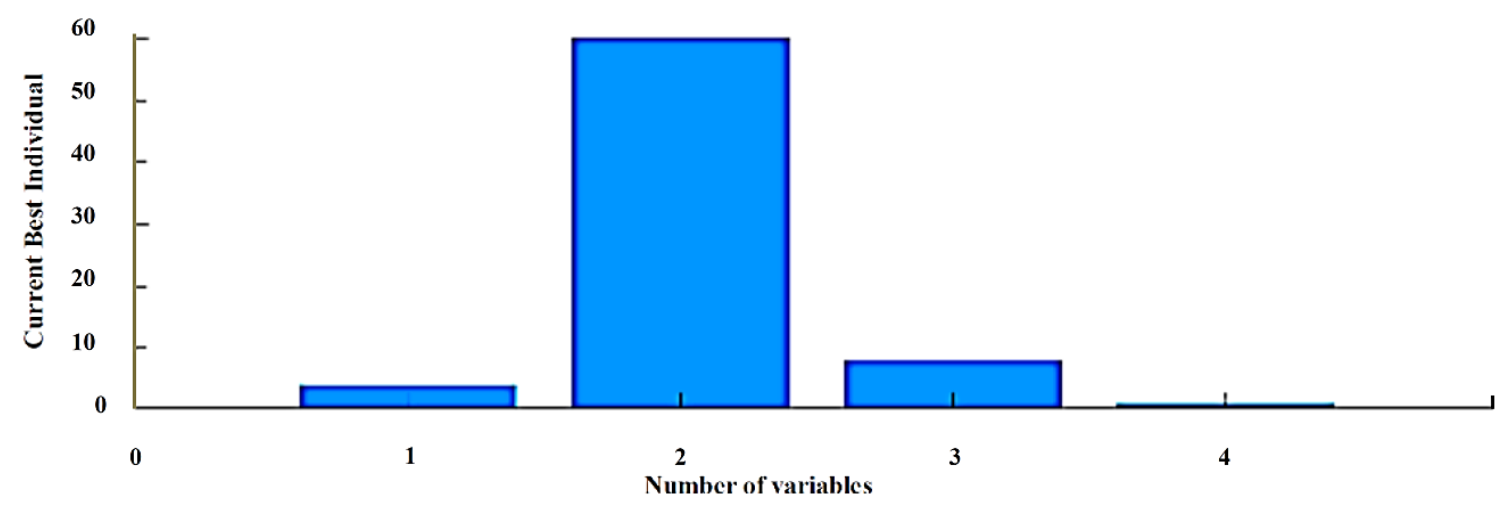

Figure 17. Best and Mean results-MRR.

Table 16. Comparison of optimized results-MRR.

\begin{tabular}{ccccc}
\hline Methods & Pulse ON $(\mu s)$ & Pulse OFF $(\mu s)$ & Current (A) & MRR (g/min) \\
\hline GA results & 60 & 8 & 1 & 0.01299 \\
Experimental results & 60 & 8 & 1 & 0.014686 \\
\hline
\end{tabular}

Figure 18 gives the X-Ray Diffraction (XRD) results of five different compositions $(0,1,2,3,4)$ wt.\% of AA7075 reinforced with MWCNTs and PFA. The graph shows the different diffraction peaks. The graph denotes that the largest peaks contain the presence of aluminium. Furthermore, the graph shows one major peak and three minor peaks for aluminium. It also indicates the presence of MWCNTs and PFA in small peaks. From the graph, it is proved that with the increase in reinforcement particles wt. \%, the intensity of reinforcement particles also gets increased. From the graph, it can also be seen that the peaks of reinforcement particles increase with an increase in wt.\%. The work in [29] shares the same XRD peaks on carbon nanotubes as a crystalline form. There is also a similar peak of CNT obtained in the aluminium matrix, in which CNT was incorporated in the aluminium matrix through the induction melting process [30]. 


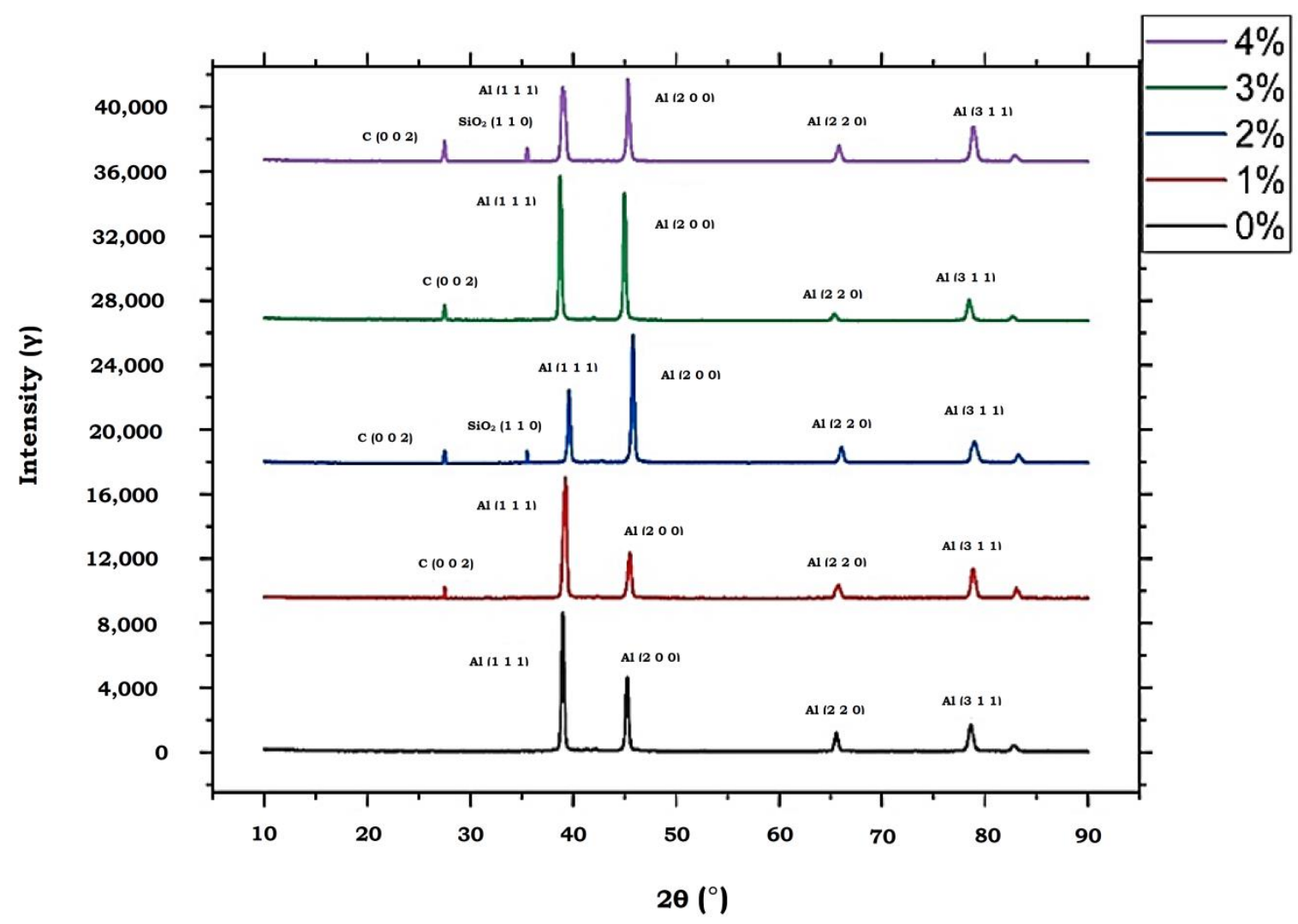

Figure 18. Intensity Vs. Degree in 2 Theta.

\section{Conclusions}

The microstructure images of various wt.\% show that the reinforcement particles are dispersed evenly in the base metal matrix. The reinforcement particles are deposited in the grain boundary, which results in the increased strength of the MMC. As the wt. $\%$ increases beyond 3\%, the agglomeration of reinforcement particles is found. Further, this decreases the strength of the alloy. The composition percentage of reinforcement affects the hardness of the material, and there exists a critical value for the percentage of reinforcement addition that starts deteriorating the synonym of tailored metal matrix composites, due to the accumulation of MWCNTs and PFA over the base matrix. Ultimate tensile strength was highest for $4 \mathrm{wt} . \%$, where the value was $165 \mathrm{MPa}$. In lower load conditions, abrasive wear was found; meanwhile, for higher load conditions it was adhesive wear. From the Taguchi analysis, it is clear that the most influencing parameters are composites (wt.\%) followed by speed (rpm), time (minutes) and load (N), that provides minimum wear rate and weight loss, as it is widely visualized through the main effects plot and signal to noise ratio. The analysis of variance of MRR shows that the percentage of contribution of weight percentage is (38.1\%), followed by current $(22.61 \%)$, pulse on $(14.1132 \%)$, and pulse off $(13.14 \%)$, indicating that the weight percentage plays an important role. The analysis of variance of wear rate shows that the percentage of contribution of weight percentage is $(82.55 \%)$, followed by speed $(9.42 \%)$, time $(4.65 \%)$, load $(2.34 \%)$. The analysis of variance of weight loss shows that the percentage of contribution of weight percentage is $(72.54 \%)$, followed by speed $(10.94 \%)$, time $(6.566 \%)$, load (3.379521\%). From the genetic algorithm for MRR, the best input process parameters were found to be composites $(4 \mathrm{wt} . \%)$, pulse on $(60 \mu \mathrm{S})$, pulse off $(8 \mu \mathrm{S})$, and peak current (1 A) for obtaining optimum MRR. Similarly, from a genetic algorithm of wear rate, the best input as composites $(4 \mathrm{wt} . \%)$, load $(10 \mathrm{~N})$, sliding speed $(250 \mathrm{rpm})$, sliding time $(5 \mathrm{~min})$, and best wear rate as 0.0005955 is the optimized response. The genetic algorithm for weight loss also gives the best weight loss as 0.001276 for the best-optimized input parameters as composites $(4 \mathrm{wt} . \%)$ load $(10 \mathrm{~N})$, sliding speed $(250 \mathrm{rpm})$, and sliding time (5 min). From XRD analysis, the highest peaks confirmed the 
presence of aluminum. The presence of MWCNTs and PFA was also witnessed using microstructure images. From the graph, it is inferred that the reinforced particles are evenly dispersed in the base metal matrix. The stratagem of this combination was aimed at fabricating the AA7075 hybrid MMC that is appropriate for aerospace, and an other wide range of applications, based on the satisfying mechanical properties and wear behavior of the synthesized composites.

Author Contributions: Conceptualization, S.K.S. and K.S.; methodology, S.K.S. and K.S.; software, S.K.S. and K.S.; validation, Y.-C.H.; formal analysis, S.K.S.; investigation, S.K.S., R.K.S. and Y.-C.H.; resources, S.K.S.; data curation, K.S.; writing-original draft preparation, S.K.S. and K.S.; writing-review and editing, S.K.S., K.S., R.K.S. and Y.-C.H.; visualization, Y.-C.H.; supervision, Y.-C.H.; project administration, Y.-C.H.; funding acquisition, Y.-C.H. All authors have read and agreed to the published version of the manuscript.

Funding: This research was partially funded by the Ministry of Science and Technology of Taiwan, grant number MOST 108-2622-E-197-001-CC2; MOST 108-2221-E-197-027; MOST 108-3116-F-024-001-CC2.

Conflicts of Interest: The authors declare no conflict of interest.

\section{References}

1. Milosevic, M.; Valášek, P.; Ruggiero, A. Tribology of Natural Fibers Composite Materials: An Overview. Lubricants 2020, 8, 42. [CrossRef]

2. Jozwik, J.; Dziedzic, K.; Barszcz, M.; Pashechko, M. Analysis and Comparative Assessment of Basic Tribological Properties of Selected Polymer Composites. Materials 2020, 13, 75. [CrossRef] [PubMed]

3. Narayanan, S.; Srinivasan, K.; Raj, J.; Noel, A. Sensor-Assisted Assessment of the Tribological Behavioral Patterns of Al-SiCp Composites under Various Environmental Temperature Conditions. Materials 2019, 12, 4004.

4. Łepicka, M.; Ciszewski, A.; Golak, K.; Grądzka-Dahlke, M. A Comparative Study of Friction and Wear Processes of Model Metallic Biomaterials Including Registration of Friction-Induced Temperature Response of a Tribological Pair. Materials 2019, 12, 4163. [CrossRef]

5. Panin, S.V.; Kornienko, L.A.; Huang, Q.; Buslovich, D.G.; Bochkareva, S.A.; Alexenko, V.O.; Panov, I.L.; Berto, F. Effect of Adhesion on Mechanical and Tribological Properties of Glass Fiber Composites, Based on Ultra-High Molecular Weight Polyethylene Powders with Various Initial Particle Sizes. Materials 2020, 13, 1602. [CrossRef]

6. Farooq, F.; Akbar, A.; Khushnood, R.A.; Muhammad, W.L.B.; Rehman, S.K.U.; Javed, M.F. Experimental Investigation of Hybrid Carbon Nanotubes and Graphite Nanoplatelets on Rheology, Shrinkage, Mechanical, and Microstructure of SCCM. Materials 2020, 13, 230. [CrossRef]

7. Panwar, N.; Chauhan, A. Fabrication methods of particulate reinforced Aluminium metal matrix composite-A review. Mater. Today Proc. 2018, 5, 5933-5939. [CrossRef]

8. Jargalsaikhan, B.; Bor, A.; Lee, J.; Choi, H. Effect of Different Raw Material Property for the Fabrication on $\mathrm{Al} / \mathrm{CNT}$ Nanocomposite Using a Ball Mill with a Discrete Element Method (DEM) Simulation. Materials 2019, 12, 3291. [CrossRef]

9. Sharma, V.K.; Singh, R.C.; Chaudhary, R. Effect of flyash particles with aluminium melt on the wear of aluminium metal matrix composites. Eng. Sci. Technol. Int. J. 2017, 20, 1318-1323. [CrossRef]

10. Prasad, K.N.P.; Ramachandra, M. Determination of Abrasive Wear Behaviour of Al-Fly ash Metal Matrix Composites Produced by Squeeze Casting. Mater. Today Proc. 2018, 5, 2844-2853. [CrossRef]

11. Suryakumari, T.S.A.; Ranganathan, S. Preparation and Study the Wear Behaviour of Aluminium Hybrid Composite. Mater. Today Proc. 2018, 5, 8104-8111. [CrossRef]

12. Deng, C.; Zhang, X.; Wang, D.; Lin, Q.; Li, A. Preparation and characterization of carbon nanotubes/aluminum matrix composites. Mater. Lett. 2007, 61, 1725-1728. [CrossRef]

13. Kumar, N.M.; Kumaran, S.S.; Kumaraswamidhas, L.A. Wear behaviour of Al 2618 alloy reinforced with $\mathrm{Si}_{3} \mathrm{~N}_{4}, \mathrm{AlN}$ and $\mathrm{ZrB}_{2}$ in situ composites at elevated temperatures. Alex. Eng. J. 2016, 55, 19-36. [CrossRef]

14. Kanth, U.R.; Rao, P.S.; Krishna, M.G. Mechanical behaviour of fly ash/SiC particles reinforced Al-Zn alloy-based metal matrix composites fabricated by stir casting method. J. Mater. Res. Technol. 2019, 8, 737-744. [CrossRef]

15. Kumar, S.D.; Ravichandran, M. Synthesis, Characterization and Wire Electric Erosion Behaviour of AA7178-10 wt.\% $\mathrm{ZrB}_{2}$ Composite. Silicon 2018, 10, 2653-2662. [CrossRef] 
16. Azarniya, A.; Safavi, M.S.; Sovizi, S.; Azarniya, A.; Chen, B.; Madaah Hosseini, H.R.; Ramakrishna, S. Metallurgical Challenges in Carbon Nanotube-Reinforced Metal Matrix Nanocomposites. Metals 2017, 7, 384. [CrossRef]

17. Nagaraj, N.; Mahendra, K.V.; Nagaral, M. Microstructure and Evaluation of Mechanical Properties of Al-7Si-Fly Ash Composites. Mater. Today Proc. 2018, 5, 3109-3116. [CrossRef]

18. Alizadeh, A.; Abdollahi, A.; Biukani, H. Creep behavior and wear resistance of Al 5083 based hybrid composites reinforced with carbon nanotubes (CNTs) and boron carbide (B4C). J. Alloy. Compd. 2015, 650, 783-793. [CrossRef]

19. Dhanasekar, G.; Faiyas, M.M. Study of Mechanical Properties of Aluminium Lm25 Using Stir Casting Method. Int. J. Eng. Appl. Sci. 2017, 4, 2394-3661.

20. Shanbhag, V.V.; Yalamoori, N.N.; Karthikeyan, S.; Ramanujam, R.; Venkatesan, K. Fabrication, Surface Morphology and Corrosion Investigation of $\mathrm{Al} 7075-\mathrm{Al}_{2} \mathrm{O}_{3}$ Matrix Composite in Sea Water and Industrial Environment. Procedia Eng. 2014, 97, 607-613. [CrossRef]

21. Baradeswaran, A.; Perumal, A.E. Wear and mechanical characteristics of Al 7075/graphite composites. Compos. Part B Eng. 2014, 56, 472-476. [CrossRef]

22. Shen, Q.; Wu, C.; Luo, G.; Fang, P.; Li, C.; Wang, Y.; Zhang, L. Microstructure and mechanical properties of Al-7075/B4C composites fabricated by plasma activated sintering. J. Alloy. Compd. 2014, 588, 265-270. [CrossRef]

23. Rajesh, K.; Mahendra, K.V.; Mohan, N.; Sachit, T.S.; AkshayPrasad, M. Studies on mechanical and dry sliding wear behaviour of graphite/flyash reinforced aluminium ( $\left.\mathrm{Al}_{6} \mathrm{Mg}\right) \mathrm{MMCs}$. Mater. Today Proc. 2019. [CrossRef]

24. Meti, V.K.V.; Konaraddi, R.; Siddhalingeshwar, I.G. Mechanical and Tribological Properties of AA7075 Based MMC Processed through Ultrasound Assisted Casting Technique. Mater. Today Proc. 2018, 5, 25677-25687. [CrossRef]

25. Kumar, G.V.; Pramod, R.; Sekhar, C.G.; Kumar, G.P.; Bhanumurthy, T. Bhanumurthy, Investigation of physical, mechanical and tribological properties of Al6061- $\mathrm{ZrO}_{2}$ nano-composites. Heliyon 2019, 5. [CrossRef]

26. Sardar, S.; Kumar Karmakar, S.; Das, D. Tribological Properties of Al 7075 Alloy and 7075/ $\mathrm{Al}_{2} \mathrm{O}_{3}$ Composite Under Two-Body Abrasion: A Statistical Approach. J. Tribol 2018, 140. [CrossRef]

27. Liang, Y.N.; Ma, Z.Y.; Li, S.Z.; Li, S.; Bi, J. Effect of particle size on wear behaviour of SiC particulate-reinforced aluminum alloy composites. J. Mater. Sci. Lett. 1995, 14, 114-116. [CrossRef]

28. Basavarajappa, S.; Chandramohan, G.; Mukund, K.; Ashwin, M.; Prabu, M. Dry sliding wear behavior of Al 2219/SiCp-Gr hybrid metal matrix composites. J. Mater. Eng. Perform. 2006, 15, 668. [CrossRef]

29. Das, R.; Bee Abd Hamid, S.; Eaqub Ali, M.; Ramakrishna, S.; Yongzhi, W. Carbon Nanotubes Characterization by X-ray Powder Diffraction-A Review. Curr. Nanosci. 2015, 11. [CrossRef]

30. Mansoor, M.; Shahid, M. Carbon nanotube-reinforced aluminum composite produced by induction melting. J. Appl. Res. Technol. 2016, 14, 215-224. [CrossRef] 